\title{
LA NECESIDAD DEL DERECHO BAJO EL PRESUPUESTO DEL IMPERATIVO CATEGÓRICO DE LA MORALIDAD *
}

\author{
Hans Friedrich Fulda \\ Universidad de Heidelberg
}

RESUMEN. En este texto, el Prof. FULDA analiza la compleja relación entre el imperativo categórico de la moralidad como principio supremo de la doctrina de la moral en su conjunto y la fundamentación de la necesidad del derecho en KANT. En la primera parte de este artículo se demuestra cómo y por qué los kantianos han malinterpretado dicha relación. En lo que sigue, se propone una solución basada en el texto kantiano: la teoría de una ley permisiva. Su rigurosa exposición pasa por una interpretación de la tabla de las categorías de la libertad descrita en la Crítica de la Razón Práctica en relación con la doctrina del concepto de un objeto de la razón pura práctica, para llegar a la conclusión de la existencia de una ley permisiva formulada con carácter expreso y en virtud de la cual se explica la relación entre derecho y moral en KANT.

Palabras clave: Hans-Friedrich FULDA, crítica de la razón pura, fundamentación de la metafísica de las costumbres, razón pura práctica, razón práctica condicionada por los sentidos, motores de la razón pura práctica, metafísica de las costumbres, categorías de la libertad, imperativo categórico de la moralidad, derecho, libre arbitrio, KANT, HEGEL.

\section{Law's Necessity under the Assumption of the Categorical Imperative of Morality}

ABSTRACT. In this text, Prof. FULDA analyses the complex relation between the categorical imperative of morality as the supreme principle of the doctrine of morality as a whole, and the groundwork of the need for Law in KANT. The first part of this article shows how and why the Kantians have misinterpreted this relationship. The rest proposes a solution based upon KANT's text: the theory of a permissive law. It's rigorous exposition streams through an interpretation of the table of categories of freedom described in the Critique of Practical Reason related to the concept-of-an-object-ofpure-practical-reason's doctrine, to conclude upon the existence of an expressly formulated permissive law by virtue of which the relation between Law and morality is explained.

Keywords: Hans-Friedrich FULDA, critique of pure reason, groundwork of the metaphysics of morals, pure practical reason, practical reason conditioned by the senses, motors of pure practical reason, metaphysics of morals, categories of freedom, categorical imperative of morality, Law, free will, KANT, HEGEL.

* Fecha de recepción: 9 de julio de 2013. Fecha de aceptación: 20 de septiembre de 2013. 


\section{PLANTEAMIENTO DEL PROBLEMA}

- 1 imperativo categórico de la moralidad es, según la «Metafísica de las Costumbres» de KANT, el «principio supremo de la doctrina de la moral» ${ }^{1}$. De ahí que haya de ser formulado en una «philosophia practica universalis» ${ }^{2}$. Es indudable que el imperativo categórico de la moralidad habría de ser determinado y defendido en aquélla, si no fuera porque esto ya había tenido lugar en La Fundamentación de la Metafísica de las Costumbres y en La Crítica de la Razón Práctica. En la philosophia practica universalis, de manera breve y concisa, dice KANT: «Obra según una máxima que, al mismo tiempo, pueda tener validez como ley universal» (op. cit.). Como principio supremo tanto de una doctrina del derecho, como de la virtud, tiene el imperativo categórico de la moralidad carácter obligatorio no sólo para todas las personas $(223,3)$ que se encuentran bajo la autonomía moral — por tanto, interna y ética- sino también para cada uno de aquellos que, en la vida en común con otros, se encuentran además sujetos a una legislación externa. Esto es, en la medida en que sus acciones externas, como conformes a una norma jurídica, no sólo son percibidas objetivamente, sino que, además, se hacen obligatorias por medio de un motor de la razón pura práctica. Dicho motor «engarza» la razón objetiva (existente en la norma), la cual es determinante para la acción, «subjetivamente con la percepción de la norma» $(218,2)$. El mencionado principio habrá de ser por lo tanto, para la doctrina de la legislación jurídica, como mínimo, relevante. Es aquél para ésta incluso tan fundamental, como para las leyes de la ética. En ningún caso, puede legislación alguna -ni, por supuesto, tampoco la externa- acarrear pretensiones que sean incompatibles con exigencias del principio supremo de la doctrina de la moral.

Las exigencias prácticas procedentes del imperativo categórico de la moralidad son, en su totalidad, obligaciones referidas a máximas de la voluntad de una determinada índole, según las cuales se obra. La legislación jurídica, por el contrario, ni posee ni proporciona obligatoriedad alguna que prohíba cualesquiera máximas como tales, o, si acaso, imponga (otras). Aquélla sólo es vinculante para acciones externas - con indiferencia de las máximas en virtud de las cuales se lleven a cabo dichas acciones o se omitan-. Es posible, por tanto, que colisionen exigencias procedentes de la legislación jurídica (por ejemplo, jurídico-positivas) con exigencias procedentes del imperativo categórico de la moralidad. En cualquier caso, dicha colisión sólo podría tener lugar en las acciones externas mismas y no en cualesquiera máximas de las cuales estas acciones puedan derivar. Y sólo en cuanto a las acciones externas ha de ser excluida la aparición de colisiones, en la medida en que éstas sean previsibles, mediante la concordancia de la legislación jurídica con el principio supremo de la doctrina de la moral. En última instancia, la evitación de la colisión sólo puede tener lugar de tal manera que, en caso de duda, el imperativo categórico de la moralidad siempre arroje una razón vinculante ( $c f r .224,3)$ más poderosa que la legislación externa particular, en tanto que la legislación externa ha de ser, de antemano, conforme con aquel imperativo

1 I. KANT, Metaphysik der Sitten. Einleitung, Teil IV, 1797, según el sistema de paginación del tomo VI de la Akademie-Ausgabe der Kantischen Werke, 226. (Más indicaciones acerca de la numeración de las páginas en $\ll[\ldots] » ; \ll$ Metaphysik der Sitten», en caso necesario «MS»).

2 Este es el título de la parte IV de la Introducción a la Metafísica de las Costumbres. 
en lo más universal. Esto último resulta imprescindible, si no se quiere que el principio supremo de toda la doctrina de la moral haya de dejar de ser una pieza integral de una philosophia practica universalis. La evitación de colisiones (hasta donde resulte inequívoco - directamente, a través del imperativo categórico de la moralidad- a lo que se refiere la obligación) habría de tener lugar del siguiente modo: Una acción externa que, por ejemplo, viniera ordenada por una determinada legislación externa, y que, no obstante, llegara a ser omitida en virtud de una máxima impuesta de modo realmente ineludible, no podría ser emprendida porque, en realidad, no se encontraría bajo ninguna legislación externa, ni bajo ninguna otra legislación que no sea la presupuesta. De tal modo que, al final, habría que hacer valer, para aquella acción externa, que se ha de obedecer más a Dios que a los seres humanos ${ }^{3}$. Además, la previsible posibilidad de colisiones entre exigencias de la legislación interna y externa, ya ha de quedar excluida a través del contenido de leyes jurídicas, para la legislación externa que no tiene carácter jurídico-positivo, sino de derecho natural. Por el contrario, otros motores de la razón pura práctica que no sean el propio respeto a la ley, han de proporcionarle a estas leyes jurídicas una obligatoriedad propia, sin, no obstante, contrarrestar dicho respeto (lo que, sin duda, resulta especialmente difícil de establecer con seguridad).

En otros ámbitos también se plantean para el «Ius», como «conjunto de las normas para las cuales es posible una legislación externa» $(\mathbb{A}$ ) fundamentada en el derecho natural, tareas que no pueden, sin más, ser tomadas en consideración en la misma medida. De estos cometidos han de rendir cuenta todos los «primeros principios de la metafísica» de una doctrina del derecho. Si existe derecho no sólo bajo un legislador que, por sí solo, tiene status de derecho público — de tal modo que sea derecho positivo - sino, más bien, cuando, más acá de ello y sirviéndole de fundamento, también forman parte de la naturaleza del derecho, como tal, principios vinculantes que anteceden a todo derecho positivo. Una división de la doctrina de la moral —en una doctrina del derecho y una doctrina de la virtud - ya ha de garantizar la ausencia de colisión de exigencias procedentes de principios de ambas legislaciones, a través de sus principios divisorios tanto en lo que se refiere a las normas mismas (en cuanto a su contenido), como a la específica obligatoriedad de dichas normas en cada caso. KANT, con buen motivo, estaba convencido de que hasta entonces la filosofía no se había planteado en serio esta tarea: «Todavía no se ha sabido, en modo alguno, determinar, para el jure naturae, su posición en la filosofía práctica a partir de principios, ni mostrar las fronteras entre aquél y la moral [...] para vislumbrar esto, hay que tratar de desarrollar los conceptos del derecho» ${ }^{4}$. Apenas diez años más tarde, se dice en una nota a pie de página de una clase: «los Principia juris han de ser muy bien diferenciados de los Principiis ethicis, lo cual Baumgarten no tuvo en consideración. La determinación del supremo principio-distintivo, que es en sí muy difícil, tampoco ha sido desarrollada, hasta ahora» ${ }^{5}$.

${ }^{3} C f r$. I. KANT, «Religion innerhalb der Grenzen der bloßen Vernunft, Viertes Stück, 1. Anmerkung, $A$. A. VI, 154. Pero también se ha de tener en cuenta la complicación planteada en el texto citado: Que la obligación unicamente por medio del imperativo categórico de la moralidad no resulta del todo evidente mientras prevalece un «estado de naturaleza ético» ¡O que, al menos, en ese estado, dicha obligación no llega a ser indudablemente consciente! (op. cit.).

${ }^{4}$ A. A., XXVII, (1321) («Naturrecht Feyerabend», 1784).

5 Ibid. (539) («Metaphysik der Sitten Vigilantius», 1793). 
Si el desarrollo tampoco nos ayuda a ver una específica obligatoriedad en leyes que, como tales, forman parte de la naturaleza del derecho, no puede ser exigible para aquéllas un carácter prescriptivo propio. Si, a pesar de esto, las mencionadas normas son expresadas en forma imperativa ( $c f r$. $\ C$ ), sólo podría verse en ello una mezcla de ley externa y legislación moral interna. En realidad y estrictamente hablando, serían de carácter no prescriptivo. Habría por lo tanto que reconocer ${ }^{6}$ honestamente, como hace M. WILLASCHEK, que, de hecho, no tienen más que este carácter no prescriptivo. Y hay que ver en ello una genuina doctrina kantiana, si no se tiene respuesta a la pregunta de dónde ha de estar situado el origen de la legislación externa pre-positiva. Mostrar que WiLlasCHEK se equivoca tanto en su planteamiento, como en los motivos, y cómo la división kantiana de la metafísica de las costumbres (en primeros principios de la doctrina del derecho y de la virtud —recíprocamente respectivos—) no sólo soluciona este problema, sino que preserva, bajo el imperativo categórico de la moralidad, el contenido tanto de normas jurídicas, como éticas - a pesar de sus distintos modos de obligar- de la colisión de exigencias resultantes de ambas sería, sin embargo, más de lo que aquí ocasionalmente puede ser emprendido.

A la suprema división de la doctrina de la moral le corresponde pues otra tarea, sin cuya resolución quedan sin sentido todas las demás tareas que han de ser resueltas a partir del principio supremo de la doctrina de la moral, además de las de la ética. Presupuesto que el imperativo categórico de la moralidad es el principio supremo de la doctrina de la moral en su conjunto: ¿Por qué existe entonces, bajo este presupuesto, derecho - más acá del derecho positivo y como su fundamentación-? Preguntado con más agudeza: ¿Existe bajo esta premisa —incluso, necesariamente- derecho? Y en el caso de que así sea: ¿Por qué para mí — que me sé situado bajo la pretensión del imperativo categórico de la moralidad, confrontado con sus exigencias, así como libre y capaz de cumplirlas - han de existir normas jurídicas, con su correspondiente legislación externa, que me obliguen no sólo a mí, sino a todos los seres racionales de la naturaleza en la misma medida - pero sólo para acciones u omisiones externas y no para determinadas máximas - cuando estos seres racionales pueden influirse unos a otros por medio de sus acciones basadas en el arbitrio? ¿Qué tipo de carácter tiene la necesidad del derecho que se manifiesta en tales ¿«Tener que»? ¿Por qué existe esta necesidad, al menos teniendo en cuenta que con KANT se considera al imperativo categórico de la moralidad principio supremo de la doctrina de la moralidad, y derecho (en el sentido de objeto de una doctrina filosófica, tal como se tematiza en el $₫$ A) al conjunto de las normas para las que es posible una legislación externa, mientras que bajo el concepto de derecho allí expuesto se entiende, en cuanto a su extensión, «el conjunto de condiciones en virtud de las cuales pueden hacerse compatibles conjuntamente el arbitrio $^{7}$ del uno con el arbitrio del otro, según una ley universal de la libertad» $(\mathbb{B})$ ?

${ }^{6}$ Cfr. M. WILlascheK, «Which Imperatives for Right? On the Non-Prescriptive Character of Juridical Laws in Kant's Metaphysics of Morals», en Kant's Metaphysics of Morals. Interpretative Essays, editado por M. Timmons, Oxford, 2002, 87. El error fundamental de WiLLASCHEK estriba en dar por supuesto que el único imperativo categórico que, según KANT, existe y puede existir es el que KANT llama imperativo categórico de la moralidad, atribuyéndole una posición prominente. Con el objeto de no fomentar este error, se utiliza en lo sucesivo, y de modo excesivamente prolijo, la complicada denominación «imperativo categórico de la moralidad», cuando se habla de aquel mandato al que otros, la mayoría de las veces, llaman «el» imperativo categórico.

7 [N. del T.]: La palabra «arbitrio» es la traducción del término alemán «Willkür» (se trata de una palabra compuesta que viene de «küren», elegir, y «Wille», voluntad) que ocupa un papel esencial en la concepción 
¿En qué consiste el supremo «principio-distintivo» entre los principios jurídicos y los «principiis ethicis», en la medida en que de ello resulta la buscada necesidad del derecho - bien sea con carácter previo, o junto a todo lo demás-? De una respuesta a estas preguntas se tratará en lo que sigue.

La respuesta, en cualquier caso, sólo podría llegar a ser exhaustiva, de tal forma que quedaran satisfechas todas las necesidades de esclarecimiento planteadas, si a las preguntas antes mencionadas se les rindiera cuenta por completo, a saber: Las preguntas acerca de todos los principios de una división de la doctrina de la moralidad; aquellas preguntas acerca de las razones por las cuales, bajo exigencias del derecho y de la virtud, no surgen colisiones, en la medida en que nuestra razón permite preverlas; y aquellas otras acerca del propio modo de obligatoriedad que tienen las normas jurídicas en su legislación, adicionalmente al que tiene el modo de obligatoriedad moral, así como acerca de las razones de aquella obligatoriedad de las normas jurídicas. En este contexto más amplio también habría que aclarar por qué por «derecho» ha de entenderse exactamente lo antes citado, que es lo que KANT expone en los $\$ \mathbb{A}$ A y B de su «Doctrina del derecho». En lugar de pretender hacer aquí todo esto, me voy a limitar a unos pocos aspectos que han de ser tomados en consideración de modo imprescindible, para nuestra comprensión acerca de la necesidad del derecho.

La clave para esta comprensión se encuentra, como habrá de mostrarse, en un lugar completamente distinto del que hasta ahora se ha supuesto. Y es que KANT, de modo desconcertante, no dedicó ninguna respuesta explícita a las preguntas antes formuladas - y que, en realidad, él mismo planteó-, a pesar de sus conscientes observaciones programáticas acerca del lugar del jus naturae en la filosofía práctica, y de la necesidad de determinar un principio supremo, para la distinción de las normas éticas de las jurídicas. Ni la «Metafísica de las Costumbres», ni ninguna otra de sus obras por él mismo publicadas da expressis verbis una tal respuesta. Ni tampoco se encuentra respuesta alguna en sus otros manuscritos que nos han sido transmitidos. El problema estriba en que KANT no podría haber dado la respuesta en toda su extensión coram publico, sin poner en evidencia a muchos de sus discípulos que, hasta doce años antes de la aparición de los «Primeros Principios Metafísicos de la Doctrina del derecho», ya habían publicado tratados acerca del derecho natural, sobre la base kantiana. Con ello, probablemente habría provocado una disputa contra sus discípulos relativa al problema de los principios. Esta disputa en el ámbito de la doctrina del derecho habría encajado todavía menos con los propósitos de popularización de KANT en el ámbito de la filosofía teórica, en el que, para disgusto de KANT, estaba en el aire entre los kantianos la disputa acerca de los principios, desde que REINHOLD se atreviera en 1789 con una nueva teoría de la capacidad de representación, y FICHTE pisara los «espinosos

kantiana del derecho. A diferencia de la voluntad pura («reiner Wille») de cuya autonomía emergen las leyes de la libertad, resulta del todo contingente para la «Willkür» que su determinación con independencia de estímulos sensibles tenga lugar o no. La «Willkür» no está por sí misma acompasada a las normas de las leyes de la libertad, y, a diferencia de la voluntad pura, optar con arreglo a dichas normas no constituye para aquélla una necesidad interna. La «freie Willkür», esto es, el libre arbitrio, es una capacidad de hacer u omitir alguna cosa de la que somos conscientes. Y somos conscientes de que dicha acción u omisión se encuentra en el ámbito de nuestra discrecionalidad y que obramos por libertad (esto es, en virtud de aquella autonomía), cuando está ordenado y actuamos en el sentido del mandato, u omitimos, precisamente, por ausencia de tal libertad. Las opciones de libre arbitrio se refieren, a su vez, a todo lo posible de lo que tenemos consciencia, y por lo que podemos decidirnos. 
senderos de la escolástica» ${ }^{8}$. Pero, quizás, KANT no se había preparado en detalle la respuesta a sus preguntas, porque él se sabía en posesión de una estrategia para el autoconocimiento filosófico de la razón práctica, por medio de la cual podría llegar a encontrar dicha respuesta ${ }^{9}$. Sea lo que fuere, las preguntas planteadas habrán de ser tratadas por medio de la interpretación. Los esfuerzos por dar una respuesta convincente van desde 1785, hasta el día de hoy. Su historia, sinuosa y muy rica en vaivenes, no puede ser contada aquí. Sólo habrán de ser discutidas y valoradas en función de sus flaquezas, y bajo puntos de vista sistemáticos, las tomas de posición que han llegado a ser las más sonadas, para no dejar que mi propósito aparezca como exageradamente prolijo. La norma para su valoración será, de acuerdo con ello y al margen de la fuerza de convicción de la cosa misma, su conformidad, o, por lo menos, su compatibilidad con las interpretaciones de KANT.

\section{RESPUESTAS INSATISFACTORIAS}

Todos los intentos de fundamentación jurídica que, en el marco de interpretaciones kantianas, o de doctrinas iusnaturalistas más o menos kantianizantes, habían sido emprendidos hasta ahora, y en los cuales se habían esgrimido aseveraciones contundentes con respecto a la necesidad del derecho, así como medios de prueba más o menos exigentes, se dejan clasificar grosso modo en: (1) intentos que tratan de alcanzar su objetivo desde el propio imperativo categórico de la moralidad, y (2) aquellos otros que, para esto (ya sea bajo la premisa de este principio, como supremo), recurren a otros principios. Los primeros asientan sus expectativas en la aplicación eficaz del imperativo categórico de la moralidad, y, a su vez, se dividen en: (1.1) intentos que argumentan directamente a partir de la fuerza obligatoria que tiene en mí, como su destinatario, el imperativo categórico de la moralidad - y esto (1.1.1), en tanto que la obligación es un mandato, o (1.1.2) en cuanto que es prohibitiva, o, no prohibitiva, pero permisiva-; por otra parte (1.2), intentos que se remiten a la fuerza que el imperativo categórico de la moralidad hace estar vigente en otros, cuya fuerza se piensa lleva aparejada consecuencias (que me otorgan derechos), de tal modo que se puede decir que estos intentos argumentaban, desde la consciencia del imperativo categórico de la moralidad, su efecto en otros, indirecta o relativamente ${ }^{10}$. Los intentos que, por el contrario, no apelan al imperativo categórico de la moralidad se distinguen fundamentalmente en aquellos que: (2.1), no obstante, quieren saber vigente este imperativo, como principio supremo de la doctrina de la moral, y un intento que (2.2) explícitamente descarta la aseveración de que el imperativo categórico de la moralidad sea este principio supremo. Algunos de todos estos intentos que bajo esta clasificación han de ser traídos a colación se distinguen a su vez, en otros aspectos, drásticamente unos de otros, de tal modo que se tiene dificultad para identificarlos en toda su configuración, como parte de la esbozada clasificación. Pero en la clasificación que aquí interesa im-

${ }^{8}$ Cfr. I. Kant, A. A., XII, (222; cfr. 221).

9 Cfr. I. KanT, Critik der Praktischen Vernunft, Riga 1788, 119 (en lo sucesivo «KpV» siguiendo el sistema de numeración de página de la citada edición).

${ }^{10} C f r$., con esa división, P. J. A. FeuerbaCH, «Versuch über den Begriff des Rechts», en F. T. NiethamMER (Hrsg.), Philosophisches Journal, 2 Bandes, 2. Heft, Neu-Strelitz, 1795, 140. 
porta, sobre todo, cuando en el contexto de la doctrina de la razón pura práctica se debate acerca de la necesidad del derecho.

1.1.1: Todavía en el año en que aparecía la Fundamentación de la Metafísica de las Costumbres publicó G. HufELAND un tratado, que se entiende a sí mismo como kantiano, sobre derecho natural ${ }^{11}$. Él pensaba que el principio del derecho natural tenía que poner de manifiesto el imperativo, procurando por medio del impedimento (en caso necesario, unido al uso de la fuerza coercitiva) «que la plenitud de todos los seres humanos no resulte disminuida» ${ }^{12}$. El imperativo debe aflorar en el camino de una conclusión inmediata a partir de una prescripción que es tenida por HuFELAND como la más universal, y que contiene la suprema norma material de la moralidad. La prescripción dice: «fomenta la plenitud de todos los seres humanos» ${ }^{13}$. Ésta, según HufELAND, se adecua perfectamente a la suprema ley formal de la moralidad de KANT.

Es evidente que ambos imperativos hufelandianos son de lo más intederminado. Eso sí, de una interpretabilidad de tal envergadura, que, en su máxima interpretación, el supuestamente más general de los principios del derecho natural en ningún caso exige, en menor medida que el mandato positivo, fomentar la plenitud de todos los seres humanos. El mencionado principio tan sólo reformula este mandato en negativo: impedir el llegar a descender del máximo en plenitud. Cualquier salvapatrias, terrorista o déspota, no esperaría a que le dijeran dos veces que puede hacer valer un principio que lleva aparejada una facultad coercitiva de tal hipertrofia, si le cambian la represión que se desprende de su poder por coacción jurídica. También es obvio que la prescripción de la que se deduce el supuesto principio más general del derecho natural no es kantiana, y que la deducción no lleva a un principio más general de derecho natural en sentido kantiano. En una interpretación minimalista de la supuestamente más general de las prescripciones morales, se puede incluso refutar que exista entre esta prescripción y el mencionado principio de derecho natural la pretendida relación de una consecuencia lógica.

Las mayores incongruencias y vulneraciones de HuFELAND contra el espíritu de un derecho natural de fundamento kantiano fueron eliminadas a comienzos de los 90 por el Catedrático de derecho de Königsberg, Th. Schmalz ${ }^{14}$. Schmalz limita en dos pasos la esfera de todas las opciones de libre arbitrio a aquellas opciones que son objeto de regulación por el derecho natural. Primero se distinguen derecho y obligación en su sentido más amplio (como lo meramente posible, y lo necesario moralmente) ${ }^{15}$, y las normas bajo las cuales se presentan de este modo, esto es, como permisivas y obligatorias, separadas unas de otras. A continuación ( $\mathbb{S} 19$ y ss.), se delimita el ámbito relevante, para el derecho natural, de lo así singularizado como posible y necesario. Esto se lleva a cabo limitando dicho ámbito a aquellas acciones u omisiones que, por una parte, son derechos u obligaciones externas y que se significan como tales porque,

${ }^{1}$ G. HufeLAnd, Versuch über den Grundsatz des Naturrechts, Leipzig, 1785.

12 Ibid., 226 y ss.; cfr., también del mismo autor, Lehrsätze des Naturrechts und der damit verbundenen Wissenschaften, Jena, $1790, \$ 74$ y ss.

13 Ibid., cfr. Lehrsätze, $\mathbb{} 72$.

14 T. Schmalz, Das reine Naturrecht, Königsberg, 1791 (1. ${ }^{a}$ ed.), 1795 (2. ${ }^{a}$ ed.). Cito según la segunda edición.

15 Esto es, lo que bajo la ley moral está ordenado en contraposición a lo que, bajo dicha ley moral, no está ni ordenado ni prohibido. 
en relación a ellas, uno tiene un derecho, otro, por el contrario - y, recíprocamenteuna obligación $(\$ 35)$, pero que, por otra parte, también son derechos u obligaciones perfectas, en la medida en que «nunca admiten excepción alguna, ni pueden ser neutralizados por medio de ninguna colisión» $(\$ 37)$. De este modo, el concepto del derecho natural se define, al igual que en KANT, como el conjunto de los derechos y obligaciones perfectas de carácter externo ( $\$ 39 ; c f r .17)$. La doctrina de ScHMALZ de un derecho natural puro también da un gran paso en el acercamiento a KANT, cuando pretende que la ciencia del derecho natural no puede, desde el punto de vista del método, ser otra cosa sino análisis de la libertad. Aquélla empieza, de acuerdo con esta afirmación, con una parte titulada «Metafísica de las Costumbres».

En Schmalz, a diferencia de HufELAND, el principio del derecho natural aparece explícitamente delimitado por el ámbito-objeto de su concepto (como conjunto de derechos y obligaciones perfectas). ScHMALZ también fue lo bastante consecuente como para determinar que los derechos y las obligaciones externas perfectas que, según su interpretación, existen bajo el supremo principio del derecho natural, presupuesto por él, no son eo ipso concebibles como aparejados a un derecho al uso de la fuerza coercitiva. De este modo, sólo están unidos a través de la premisa de que otros vulneran sus obligaciones perfectas de carácter externo o amenazan vulnerarlas. Además de esto, el concepto de un derecho a la fuerza coercitiva ha de ser, antes que nada, deducido del supremo principio del derecho natural (18 y ss., $\mathbb{\$}$ 9), para lo cual ya ha de presuponerse un concepto del derecho.

Pero, lamentablemente, SCHMALz tampoco limita el derecho al uso de la fuerza coercitiva a las condiciones esbozadas más adelante por KANT (en $\mathbb{S}$ B y C), para las acciones que son jurídicamente correctas. Esto se debe, sobre todo, a que no tiene en cuenta la consecuencia que se deriva de una norma permisiva, para la descripción, con arreglo a ésta, de los distintos supuestos de hecho. Además, imita la forma de proceder de HuFELAND en lo que se refiere a la deducción del supremo principio de derecho natural. Para ello, sin embargo, no parte de la prescripción perfectibilística de HufELAND, sino de la fórmula finalista del imperativo categórico de la moralidad: «trata a la humanidad, sea en ti o en otros, no como simple medio, sino siempre como fin» (\$13). Pero él cree poder concluir, a partir de esta fórmula y a través del supremo principio del derecho natural, que el contenido conceptual del «mandato general de la naturaleza humana» considerado en la fórmula finalística se descompone doblemente. Primero, en una parte que sólo considera los fines y otra los medios. A continuación, esta segunda parte que, a su vez, se divide en una que se refiere a la humanidad en mí mismo, y otra que concierne a la humanidad en otros. Y esta última parte ha de valer, para supuestos de posibles acciones respecto de las cuales cabe pensar, sin excepción alguna, derechos y obligaciones recíprocamente distribuidos entre personas. De este modo debe deducirse el supremo principio jurídico, a partir de la fórmula finalística del imperativo categórico de la moralidad, trivialmente, pero exclusivamente referido a derechos y obligaciones perfectas de carácter externo, y decir: «Nunca trates a la humanidad en los demás como simple medio» (\$39). Con ello quiere ScHMALZ rendir cuenta de la convicción de que el derecho nunca puede ordenar fines.

La manera de seguir el citado principio sin tratar a los demás (aquellos sobre cuyo arbitrio el uso del propio ejerce una influencia), al mismo tiempo, como fines —algo 
que, por tanto, forma parte de la específica materia de una obligación ética- es un secreto de SCHMALZ. ¿Consiste quizás el secreto en que los demás no puedan ser simples medios, para mis propios fines egoístas, pero que en el marco del derecho natural sí puedan ser, para mí, nada, de tal manera que cumplo con el presunto principio, si no me ocupo de las consecuencias que mi acción tiene para los demás, esto es, si no contemplo estas consecuencias en ningún momento, por las ventajas que puedan tener para mí? En ese caso no trato a la humanidad en otros como simple medio. Pero incluso, si el secreto pudiera ser revelado de otra forma, cabría objetar que, según este principio, no podrían existir obligaciones jurídicas «internas», o contra uno mismo ${ }^{16}$, habida cuenta que este tipo de obligaciones jurídicas no comprometen mi arbitrio a un determinado trato de la humanidad que hay en otros, sino en mí. Tampoco resulta plausible la afirmación $(\$ 40)$, según la cual, el supuesto principio supremo del derecho natural es «la única condición bajo la cual los seres racionales pueden coexistir en libertad». La debilidad del tejido, en el que el concepto general del derecho y supremo principio del derecho natural ha de ser deducible, directamente, a partir del imperativo categórico de la moralidad, se hace patente. Y esto, precisamente, a través de la constatación de que el concepto de un derecho al uso de la fuerza coercitiva necesita ser deducido, pero que, para su deducción, ya ha de ser presupuesto el concepto de un derecho, entendido jurídicamente, que alguien tiene para llevar a cabo su acción.

Dicho de otro modo: la supuesta deducción no procede en modo alguno de sus casillas de salida, sino que, en el mejor de los casos, se aproxima a conceptos de lo especialmente permitido moralmente (a diferencia de lo que está permitido, bajo prescripciones de la razón práctica condicionada por los sentidos), y a conceptos de normas morales, pero no obligatorias sino permisivas, para clases especiales de posibles opciones puestas en el arbitrio ${ }^{17}$. Incluso con respecto a estos resultados, del todo insuficientes para el fin de la deducción, habría de haber sido tomada en consideración la advertencia kantiana de que en el enjuiciamiento moral se obra mejor procediendo siempre, según el método más estricto y poniendo a la base la fórmula general del imperativo categórico de la moralidad ${ }^{18}$. En cualquier caso, para una fundamentación del derecho, se echa todo a perder de antemano con el recurso a la fórmula finalista del imperativo categórico de la moralidad, puesto que en el concepto del derecho ha de prescindirse explícitamente $(\mathbb{B})$ del aspecto material del arbitrio, y, con ello, de toda finalidad. Pero esto último no es posible, si (supuestamente) está ordenado no tratar nunca a nadie como simple medio, ya que esto significa: «nunca simplemente como medio para cualesquiera fines».

Por ello, resulta comprensible que inmediatamente después del libro de ScHMALZ fueran emprendidos (ver más adelante) intentos de deducción indirecta del derecho (1.2). El problema es que estos intentos tampoco eran capaces de procurarse fuerza de convicción alguna, y las sustitutivas renuncias a fundamentaciones procedentes, di-

16 ¡Cfr., contrario a ello, I. KANT $(236,5)$ !

17 Lo que con ello se hubiera podido hacer, se habrá de mostrar más adelante. Como consecuencia de que lo permitido bajo una ley permisiva se difuminaba con lo permitido indiferentemente y que se mezclaba con un principio del derecho natural que no tenía utilidad, quedaba hasta ahora sin consecuencias en toda la discusión acerca de la fundamentación kantiana del derecho.

${ }^{18}$ Cfr. I. KanT, Grundlegung zur Metaphysik der Sitten (436, u.). (Sistema de numeración de páginas según A. A. IV. Berlín, 1903). 
recta o indirectamente, del imperativo categórico de la moralidad parecían aún menos plausibles. Esto dio lugar a que, en la segunda mitad del siglo veinte, se renovaran los esfuerzos por una fundamentación directa. Se intentó, en primer lugar, tomar al imperativo categórico de la moralidad estrictamente como principio formal (por lo tanto, no como reflexión que exige fines). Así empezó J. EbBinHAus ${ }^{19}$. Junto a su loable fidelidad a KANT pretendió, no obstante, extraer del fracaso de los intentos de fundamentación que partían de premisas más ricas en contenido (a discutir en 1.1.2, 1.2 y 2.1) la fatal consecuencia que la doctrina del derecho de KANT es completamente independiente de los decisivos resultados de las dos primeras críticas ${ }^{20}$. Según EBBinHAus, el problema de la libertad comienza más allá de la doctrina del derecho ${ }^{21}$. Con ello se cerraba el camino para una mejor evaluación de la distinción de SCHMALZ entre normas obligatorias y permisivas, para la fundamentación del derecho. Todo ello a pesar de que esto ya se había logrado con anterioridad (en SCHMALZ y en los planteamientos que han de ser discutidos más abajo), y se había conseguido enderezar estos planteamientos, por medio del potencial de fundamentación procedente del concepto de libertad de la filosofía crítica. El desacierto de sus propias indicaciones, para la fundamentación del derecho, están en consonancia con el mencionado problema.

Ahora resulta del todo incomprensible lo que deba justificarse bajo la premisa de EBBINGHAUS: legislación jurídica y moral en KANT, pero considerando sus preceptos como normas de la libertad, y normas éticas. Los principios fundamentales de la doctrina de las normas jurídicas hay que buscarlos, según EBBINGHAUs, en una Metafísica de las Costumbres, que, además, contiene mucho más doctrina del derecho que en SCHMALZ. Si EBBINGHAUS tuviera razón, habría que aceptar la monstruosa pretensión de que el derecho se encuentra bajo el imperativo categórico de la moralidad, lo cual no significa otra cosa sino que el derecho sería «una máxima de la determinación de la libertad del arbitrio, en cuanto a su relación externa» ${ }^{22}$ ¡El derecho, una máxima impuesta, como cualquier otra máxima moral, por la norma moral, cuya exigibilidad viene expresada a través del imperativo categórico de la moralidad! ${ }^{23}$ ¿Acaso existen máximas, en las cuales el arbitrio no esté fijado sobre un determinado fin, ni sobre un determinado motivo para su observancia, sino solamente sobre una acción intencional en una determinada situación, aunque, como máximas, sí sean supremos principios subjetivos que se proyectan sobre toda la vida futura, motivados de una determinada manera, y, con ello, acciones dirigidas a fines? ¿O no es el derecho nada diferente de la determinación ética de la voluntad, ni del funcionamiento del arbitrio, cuando dicho funcionamiento sólo está referido a la relación externa de la persona? El derecho no

19 Cfr. en especial J. EBBinHaUs, «KANT und das 20 Jahrhundert», 1954, así como «Kants Rechtslehre und die Rechtsphilosophie des Neukantianismus», 1960. En J. EbBIngHaUs, Gesammelte Schriften, Hrsg. V. H. Oberer/G. GeISMAnN, Bd. 3, Bonn, 1990, 167; Bd 2, Bonn, 1988, 242.

20 Ibid., Ges. Schr., Bd 2, 232.

21 Ibid., Bd 3, 168.

22 «La cual, a través de la ley que exige que las máximas de nuestras acciones puedan ser pensadas como leyes universales, se hacen necesarias» (ibid., «Kants Rechtslehre und die Rechtsphilosophie des Neukantianismus», 242).

23 En contra de ello, dice KANT expresamente que este imperativo es «una proposición que ordena una obligación, a partir de la cual» puede ser desarrollada la capacidad de obligar a otros; y KANT interpreta esta capacidad como «el concepto del derecho» que alguien puede tener, esto es, como el derecho «subjetivo» (239). 
sería, de este modo, algo con lo que se pudiera uno aclarar que sea un conjunto de normas (como contenido de la doctrina del derecho). Pero, además, de normas para las que es posible una legislación externa $(\mathbb{A}$ ). . Ni tampoco se podría aclarar el derecho como el conjunto «de las condiciones bajo las cuales pueden llegar a hacerse compatibles conjuntamente el arbitrio del uno con el arbitrio del otro, según una ley universal de la libertad»; antes que nada, en cuanto a «una correspondiente obligatoriedad» $(\S B)$ para este concepto del derecho. Un tal conjunto, es decir, complejo de condiciones, es esencialmente más, y tiene que ser bajo su concepto algo «otro» que una determinada «máxima», esto es, regla de un agente que por razones subjetivas hace de esta máxima un principio para sí mismo (225). La razón que EBBINGHAUS nos señala, para construir la máxima de la que se trata, también es general, a saber: que, obviamente, no cabe pensar una máxima como ley de la libertad externa, según la cual, la libertad de cada uno pueda estar en todo momento discrecionalmente en conflicto con la de otro (ibid., II, 242). Según un criterio tan débil, esto es, que lo diametralmente opuesto a la posible máxima moral no pueda ser pensado como una ley universal, tendrían que pasar por jurídicas aquellas normas, en virtud de las cuales una banda criminal proceda entre sus miembros y frente a terceros. Los demás pasajes en los que EBBINGHAUs hace referencias a la deducción del derecho (como máxima) a partir del imperativo categórico de la moralidad no resultan, en modo alguno, más convincentes ${ }^{24}$.

Esta insuficiencia de las alusiones de EBBINGHAus, para la fundamentación del derecho, sólo sería superable, si se argumentara que, quien en virtud del imperativo categórico de la moralidad está moralmente obligado, lo está también a la legalidad de sus acciones, y que «legalidad de las acciones externas» viene a ser lo mismo que «conforme a derecho» e «ilegalidad de las mismas» infracción de una norma jurídica. Con este argumento, no llegamos ni a una ley específicamente jurídica, ni a su correspondiente norma — a diferencia de una ley para máximas de la que partíamos-. Tampoco llegamos ni a una obligatoriedad específica, ni a un motor de la razón pura práctica específico, para la obediencia de la ley. Todo esto queda oculto en la forma escueta de exponer el argumento. Ahora bien, resulta del todo refutable la pretensión de que el moralmente obligado lo esté, como tal, a la legalidad de sus acciones, puesto que la legalidad de sus acciones es una consecuencia de la determinación moral de su voluntad, o de otras razones que no son razones morales de la determinación de la voluntad, pero no el objeto de su obligación en virtud del imperativo categórico de la moralidad. Pero, sobre todo, es falsa la pretensión de que una acción externa que posea mera legalidad (moral) venga a ser lo mismo que decir que es conforme a derecho.

En el fondo es bastante sencillo de ver que todos los intentos de fundamentación del derecho que argumentan a partir de la fuerza imperativa del imperativo categórico de la moralidad han de fracasar. Si entienden este imperativo como fundamento material, no se liberan en la conclusio del fin que está pensado en la premisa, pero que en el derecho no ha lugar. $\mathrm{Si}$, por el contrario, toman al imperativo, de modo consecuente, como fundamento formal, cualquier principio que sea directamente deducible de ello será un principio para máximas, cuya consideración, a su vez, no ha lugar en el derecho natural.

${ }^{24}$ J. EbBinghaus, «Luther und Kant», 1927, en Ges. Schr., Bd 3, ibid., 54 y ss.; «Die Idee des Rechts», en ges. Schr., Bd 2, ibid., 173. 
1.1.2: ¿No será, en tales circunstancias, más halagüeño argumentar a partir de lo que el imperativo categórico simplemente permite, en la medida en que no lo prohíbe, o ni prohíbe ni ordena? El primero en confiar en esta estrategia argumentativa fue J. G. FICHTE quien en 1793 decía: «En cuanto a lo que la ley moral ni ordena ni prohíbe, sino simplemente permite, tenemos un derecho a hacerlo, aunque también a no hacerlo» ${ }^{25}$, es decir, que la ley moral sería, como regla de lo permitido, el fundamento deductivo de la diferenciación entre el derecho y la obligación existente al amparo del imperativo categórico de la moralidad. FICHTE parece entender por «derecho» el derecho subjetivo que uno tiene, en el sentido de que sólo de este modo cabe hablar razonablemente de derecho. Como ser racional, el ser humano se encontraría, según FICHTE, única y exclusivamente sometido a la ley moral (que se manifiesta en el imperativo categórico de la moralidad). A ningún ser le estaría permitido incurrir en la osadía de imponerle otra ley. Y a él mismo le estaría igualmente prohibido reconocer otra ley, además de ésta, que no sea la del arbitrio. Por lo tanto, el «derecho» del que habla FICHTE también prescinde de toda obligatoriedad que, como «derecho» de otros frente a mí, tan sólo sería un derecho concedido por mí a estos otros a partir de mi arbitrio. Del mismo modo que mi derecho frente a ellos no sería más que algo que éstos me conceden a mí, en virtud de su arbitrio. Ambos aspectos se basan exclusivamente en la coincidencia del arbitrio. De ahí que, si se da, no sea más que un factum social contingente y, en modo alguno, necesario, como tampoco un conjunto de leyes para las que sea posible una legislación externa. La «deducción» es, con otras palabras, negación de toda necesidad (sea teórica o práctica) del derecho y, al mismo tiempo, la desestimación del planteamiento kantiano de un derecho que precede a la formación de una comunidad jurídica, que la hace posible al amparo de leyes referidas a la acción externa, y, para las que, no obstante, es posible una legislación externa, aunque todavía no constituyan eo ipso la fundamentación de un estado de cosas jurídico entre seres humanos.

El tajante decisionismo de FICHTE, que reduce el derecho a una convención social, no iba a ser sostenido por otros (el propio autor lo sometió a revisión tres años más tarde). El problema es que el argumentario movilizado en esta tarea no llevaba a la comprensión de la necesidad del derecho, y, mucho menos aún, a la concepción kantiana. Tras el fracaso de intentos concebidos de otro modo (a discutir en 1.2 y 2.1) pensaba, por ejemplo, el neokantiano W. HAENSEL ${ }^{26}$ que aquel que está sometido a la ley moral y, como consecuencia de ello, obligado en su interior a la realización de un deber tiene la facultad de imponerle a otros la obligación de no ponerle impedimentos en el cumplimiento de este deber. A partir de este «estarle a uno permitido» que de este modo se legitima, ha de darse tanto la limitación del derecho a la regulación interpersonal de la determinación del arbitrio, para acciones externas bajo el aspecto de su mera legalidad, como la autorización para imponer a otros la legalidad en caso de acciones ilegales (reales o en potencia, y, por lo tanto, constitutivas de amenaza). De esta permisión, también ha de derivarse el concepto de una legislación externa que no procede del destinatario de la obligación y que, sin embargo, constituye actividad autónoma de la razón ¿Pero por qué habría de ser esta legislación necesaria, si no se

25 «Beitrag zur Berichtigung der Urteile des Publikums über die Französische Revolution», en Werke, hrg. v. I. H. FiCHTE (1834-46), Bd. VI, 60 y ss.

${ }^{26} \mathrm{Cfr}$. W. HAENSEL, Kant und das Widerstandsrecht. Ein Beitrag zur Systematik der kantischen Rechtslebre, Berlin, 1926, 13 y ss.; K. KüHL, Eigentumsordnung als Freibeitsordnung, Freiburg, 1984, 53 y ss. 
apoya más que en una permisión? Y viceversa ¿Por qué, al amparo de esta legislación que permite obligar a otras personas, no está esto ordenado? La legislación externa no sólo permite, sino que también manda y prohíbe ¿Por qué esta legislación permite obligar a otros y no a sí mismo? ¿Por qué ha de estar referida esta permisión — de estar fundamentada tal y como se presume- solamente a las acciones externas de otros bajo el aspecto de su vulneración de la legalidad (moral), y no igualmente a acciones internas que del mismo modo puedan constituir un impedimento para otros en el cumplimiento de obligaciones morales?

Pero, sobre todo: ¿cómo y por qué resulta de la obligación interna en virtud de máximas, las cuales responden a las exigencias del imperativo categórico de la moralidad, que, para llevar a cabo las acciones descritas en las máximas, se pueda obligar a otros a no impedir dichas acciones? El imperativo de ningún modo se refiere a una obligación, cuya realización vaya más allá de la formación de la máxima ordenada. La exigencia de construir la máxima ordenada o, al menos, no prohibida queda satisfecha por medio de mi fuerza moral. Ésta consiste en tomar en consideración la máxima correspondiente (en cuanto a la forma), para la ley que me obliga internamente, incluso en casos difíciles. Dicha máxima no se cumple por el hecho de que, además de mi resistencia interna, sea vencida la resistencia externa que oponen otros a mi correspondiente acción. Cabe una excepción, a saber: que la rotura de una eventual resistencia externa esté contenida en una máxima que presente la forma exigida, la cual haya sido asumida por razón de la forma. El problema es que entonces no me está simplemente permitido, sino internamente ordenado. Sin embargo, en ninguno de ambos supuestos, resulta otro moralmente obligado a no impedir dicha acción, ni por medio de mi acción que se deduce de mi máxima, ni tampoco a través de la propia máxima. Esto en la medida en que toda obligación moral es, por medio del imperativo categórico, exclusivamente auto-obligación del obligado moralmente, a través de su propia razón pura y de su actividad legislativa interna. El concepto de los «derechos como facultad (moral) para obligar a otros» ${ }^{27}$ no se deriva directamente, es decir, sin una razón adicional, del imperativo categórico de la moralidad. El paso fundamental emprendido, para la pretensión acerca de la necesidad del derecho, es en realidad un non sequitur. $\mathrm{Y}$ es que, aunque no lo fuera, la obligatoriedad de las exigencias que han de fundamentarse, por medio de este paso, sólo existiría allí donde alguien cumple obligaciones morales, y solamente en función de dicho cumplimiento. Esto es, no existiría precisamente como obligatoriedad de una exigencia de tipo jurídico, ni tampoco sin un fin, en cuya función (de realización) se encuentra este presunto derecho.

A medida que el efecto EBBINGHAUs iba cejando, fueron emprendidos, de nuevo, intentos de fundamentación del derecho, sobre la base de la permisión que el imperativo categórico de la moralidad me concede o parece concederme. Estos intentos empiezan con el revolucionario libro de W. KERSTING ${ }^{28}$. El propio KERSTING, de modo convincente, vincula a dicha permisión la conclusión de que así no es posible llegar, en continuidad epistémica, desde el imperativo categórico de la moralidad al concepto, principio y norma universal kantiana del derecho. ${ }^{29}$ De ahí que su idea de la funda-

\footnotetext{
$27(237,4)$.

28 W. KERSTING, Woblgeordnete Freibeit, Berlin, 1984.

29 Ibid., 30 y ss.; cfr., ibid., Kant über Recht, Paderborn, 2004, 40 y ss.
} 
mentación se concentre, de antemano, en la pregunta iusnaturalista tradicional acerca de las condiciones moralmente admisibles, para el empleo de la fuerza coercitiva contra otros. Por lo tanto, según KERSTING, la permisión de obligar a otros mediante el uso de la fuerza coercitiva precede tanto al concepto y principio, como a la norma universal del derecho kantiano. Esta permisión ha de resultar de una permisión aún más principal: la de reflexionar la norma fundamental de la razón pura práctica no siempre en relación con motivos internos determinantes para el arbitrio, sino también «desde una perspectiva extramoral» ${ }^{30}$. Con ello, la ley jurídica universal y la legislación de la razón que se le atribuyen tienen carácter general, esto es, no solamente son cognocibles a través del planteamiento elegido para la fundamentación — presuntamente secundarioen relación a la autorización del empleo de la fuerza coercitiva, y cuyo conocimiento sólo tiene lugar como una consecuencia del uso de dicha fuerza. Sin embargo, según la interpretación de KERSTING, se puede ver con claridad que la función legislativa que le viene atribuida al derecho renuncia a la idea del deber solamente «para hacerle sitio a la posibilidad del uso de la fuerza coercitiva en el ámbito de las acciones que constituyen mandatos jurídicos» ${ }^{31}$. De este modo, le confiere «al desdoblamiento de la legislación de la razón no sólo plausibilidad, sino también necesidad» (op. cit.), de forma que la norma jurídica (constituida por el contenido de una de las dos funciones legislativas) y el derecho al amparo de la misma hayan de ser necesarios.

Como se puede ver, lo que subyace —además de lo que se entiende como una necesaria mejora de KANT - es una sutilizada y radicalizada variante del argumento haenseliano a favor de una permisión jurídica supuestamente fundamental de hacer obligatorio, para otros, el no impedir el cumplimiento de obligaciones morales. La mayoría de las objeciones formuladas van referidas a esta variante. Pero los matices, a través de los cuales dicha variante se singulariza, la hacen vulnerable a mayores objeciones ${ }^{32}$. Como consecuencia de una permisión, que, en el mejor de los casos, lo es de lo indiferente (es decir, una permisión de lo que ni está ordenado, ni prohibido, $c f r$. [223]) y que, originariamente, $(i)$ no es más que la (supuesta) permisión de situarse en una determinada perspectiva (!), ha de tener la legislación externa (con su correspondiente abstracción de motivos y fines) carácter necesario. Y esto, incluso, en el contexto de una fundamentación que adolece de la falta de una relación teleológica

30 Ibid., 28, 3 -haciendo referencia a la «Metaphysik der Sitten» (214, 2)—. Allí se dice, en analogía al espacio —donde sólo hay objetos de los sentidos externos - y al tiempo — en el que los objetos lo son tanto de los sentidos externos como internos- que las leyes de la libertad — se contemple ésta «en el uso externo o interno del arbitrio»— «como leyes prácticas de la razón pura para el libre arbitrio en general, han de ser al mismo tiempo, para éste, motivos internos determinantes; aunque no siempre han de ser contempladas en relación a este aspecto». La formulación kantiana en la que KERSTING se apoya deja abierto si la consideración de las leyes de la razón pura práctica, en la cual éstas no son tomadas como motivos internos de determinación del arbitrio, es meramente posible o si se trata de una consideración necesaria cuyos motivos, en el contexto de la analogía que se pone de manifiesto, son irrelevantes. De ahí que no contenga lo que KERSTING pretende. Pero por otra parte el contexto hace improbable que nos encontremos ante la alternativa entre posibilidad moral y necesidad, por lo tanto, entre permisión y obligación en el ámbito de una ley de la libertad. La consideración de la libertad «en el uso externo o interno del arbitrio» que tiene ante sí, al mismo tiempo, leyes de la libertad en uno u otro respecto se encuentra, al igual que la percepción de objetos mediante el funcionamiento del sentido externo e interno, en una situación, en la que la realización de una de las dos opciones de la alternativa no está a disposición del arbitrio.

31 W. Kersting, Woblgeordnete Freiheit, ibid., 33.

$32 \mathrm{Y}$ esto añadido a lo cuestionable de la interpretación kantiana en la que KERSTING se apoya (cfr. con la nota 29). 
entre la renuncia (a la auto-obligación interna) y la autorización al uso de la fuerza coercitiva. Pero, si, a partir de esa permisión, se pudiera hacer visible la necesidad del derecho, la propia autorización al uso de la fuerza coercitiva ya tendría que ser una autorización jurídica, esto es, habría de presuponer el concepto del derecho, así como la obligatoriedad de las pretensiones jurídicas que presumiblemente resultan de aquella permisión. KANT lo piensa, exactamente, tal y como en el argumento de KERSTING habrían de estar ordenados los fundamentos para hacerlo viable. Pero es que, además, el propio KERSTING piensa los fundamentos, sin quererlo y sin darse cuenta, del mismo modo. Se supone que también hay una razón, a saber: existe una renuncia (a la idea de obligación como motor de la razón pura práctica), para (a) que acciones procedentes de mandatos jurídicos (b) sean susceptibles de ser impuestas por medio de la fuerza coercitiva. Esto es, acciones, cuya determinación jurídica les viene dada no por la autorización al empleo de la fuerza coercitiva frente a otros, sino que (al igual que en la ordenación conceptual asumida por KANT) ya han de estar previamente singularizadas jurídicamente, para poder ser conceptuadas como susceptibles de ser impuestas por medio del empleo de la fuerza coercitiva. KERSTING quiere embridar el caballo (de la fundamentación de un concepto, ley y principio general del derecho) por el rabo (de la autorización al uso de la fuerza coercitiva) haciéndole a KANT el reproche de proceder en sentido contrario. El problema es que el caballo se le rebela y da al traste con su torpe intentona.

Parte de la crítica adicional que se le puede hacer a KERSTING ya había sido formulada por K. STEIGLEDER ${ }^{33}$. El intento de STEIGLEDER de arrojar luz en la oscuridad de una fundamentación kantiana del derecho pone de manifiesto que moral, derecho y ética no sólo se distinguen, en cada caso, por las respectivas normas y vínculos específicos, sino preferentemente por las distintas predisposiciones en las que se encuentran aquellos que son destinatarios de la respectiva legislación ${ }^{34}$. Eso es, sin duda, del todo cierto. De otro modo, las pretensiones jurídicas sólo podrían ser vinculantes para aquel que se somete al imperativo categórico de la moralidad, es decir, para aquel que asume el punto de vista exigido por este imperativo. Otro tanto de lo mismo sucedería con las potestades jurídicas. Me parecen casi del todo acertadas tanto la diferenciación que hace STEIGLEDER entre los dos puntos de vista, como su caracterización de la predisposición que es propia del derecho. Pero, para la fundamentación del derecho, pretende STEIGLEDER llegar directamente (en un salto todavía mayor que el de KERSTING) a la necesidad jurídica, desde la reflexión acerca de lo que al amparo del imperativo categórico de la moralidad es necesario y posible. Y no sólo, como KeRSTING, quien por encima del concepto, principio y norma general del derecho, llega inmediatamente a la autorización del uso de la fuerza. STEIGLEDER quiere, incluso por encima de esto, llegar directamente al derecho innato que aparece al final del prolegómeno de la doctrina kantiana del derecho. Que esto no contribuye a la solución del problema de la fundamentación del derecho va de suyo.

En los intentos contemplados bajo 1.1.2 se percibe, en general, que partiendo del imperativo categórico de la moralidad no es posible llegar a la comprensión de la ne-

33 K. STEIGLEDER, Kants Moralphilosophie. Die Selbstbezüglichkeit reiner praktischer Vernunft, Stuttgart, 2002, 152 y ss.; 155.

34 Ibid., 136 y ss. 
cesidad del derecho, si se atiene uno a lo que al amparo de este imperativo, como no prohibido o, ni ordenado ni prohibido, está permitido. El concepto de lo que de este modo resulta permitido de ninguna manera se refiere sólo a acciones externas, ni, mucho menos aún, solamente a aquellas que puedan influir en el arbitrio de otras personas. Al ámbito del imperativo categórico de la moralidad pertenecen, más bien y además, acciones internas, predisposiciones, motivos y fines. Dicho imperativo no nos suministra, con la mejor voluntad, una razón necesaria y suficiente para hacer abstracción de las mencionadas acciones, predisposiciones, motivos y fines. Pero la abstracción es necesaria no sólo para el concepto del derecho, sino para la norma jurídica universal, y el concepto de lo permitido jurídicamente. Todos los intentos de deducción que parten directamente del imperativo categórico de la moralidad como regla de lo permitido dejan sin explicar la razón de la necesidad de esta abstracción. No buscan un principio de separación entre la doctrina del derecho y la doctrina de la virtud, que sea simétrico al de la separación de la doctrina de la virtud de la del derecho $^{35}$. De ahí, que tampoco caigan en la cuenta de que precisan de una doctrina de la permisión mucho más específica que la que tienen a su disposición. Pero en lugar de legitimar y hacer valer el concepto de lex permisiva traído a colación por SCHMALZ, lo han olvidado o nunca lo han conocido.

1.2: Un año después de SCHMALZ, emprendió K. L. ReINHOLD su Intento de una Nueva Exposición de los Principios y Conceptos Fundamentales de la Moral y del derecho Natural ${ }^{36}$. Descartó, con razón, el programa consistente en deducir un fundamento del derecho natural a partir de la fórmula finalista del imperativo categórico de la moralidad. Eso sí, tampoco aceptó la sugerencia de ScHMALZ (que probablemente se retrotrae a $\mathrm{KANT}^{37}$ ) de reflexionar acerca de una ley permisiva que coordine al imperativo categórico de la moralidad, pero que dependa de la consciencia del mismo y que sea necesaria, incluso bajo el presupuesto de dicho imperativo. En lugar de esto, inició la serie de intentos de una llamada deducción relativa del derecho. Para evitar la confusión entre moral y derecho natural ${ }^{38}$, REINHOLD tuvo en consideración, incluso de forma más extensa que SCHMALZ, planteamientos que hubieran debido llevar a este último hacia el concepto del derecho natural. Ahora bien, dichos planteamientos considerados como tan sólo capaces de suministrar un concepto del derecho «en el sentido más estricto», del cual, el del derecho natural ha de desprenderse. Pero incluso REINHOLD llega desde aquí al derecho natural y a su principio supremo, solamente, por medio de un quid pro quo. La ley moral, según él, impone a otros la obligación moral de no compelerme por la fuerza. En esa misma medida me otorga (a mí) el derecho (moral) a no dejarme obligar por la fuerza coercitiva. Y el hecho de que a otros, en virtud de la ley moral, les esté prohibido obligarme por la fuerza, arbitrariamente y para la mera satisfacción de su impulso egoísta, me coloca a mí en la posición de hacer valer mi derecho a no ser obligado coercitivamente, por medio de la fuerza coercitiva que ejerzo sobre aquéllos. El derecho sería en este caso, según REINHOLD, el derecho al empleo de la fuerza coercitiva, y vendría, por lo tanto, «determinado por la ley mo-

35 ¡Cfr. con I. KANT, «MS» $(406,3)$ !

36 K. L. ReInHOLD, «Versuch einer neuen Darstellung der Grundbegriffe und Grundsätze der Moral und des Naturrechts», en Briefe über die kantische Philosophie, Zweyter Band, Leipzig, 1792. Como carta VI.

37 Ibid. «MS» (223).

38 ¡Cfr., ibid., ZifF. 41! 
ral». Si, además, se dan las condiciones adicionales, para que este derecho aflore por medio del factum de la fuerza coercitiva de la que soy sujeto pasivo, y para que a la respuesta a esa fuerza coercitiva no se le oponga una obligación de conciencia, según la cual dicha fuerza coercitiva haya de ser tolerada, entonces el derecho al empleo de la fuerza coercitiva sería el derecho natural o derecho Natural. Su primer principio dice: «estás autorizado a neutralizar por medio del empleo de la fuerza coercitiva a quien haciendo uso de la misma te compele, para la mera satisfacción de su impulso egoísta» (ZIFF, 41).

Con ello y de modo distinto a como lo hace SCHMALZ, el derecho natural es concebido de tal forma que no sólo coincide en su extensión con el derecho al empleo de la fuerza coercitiva, sino que el concepto de autorización al uso de dicha fuerza adquiere, para el concepto del derecho natural, carácter definitorio. Además del mencionado quid pro quo y de la definición por medio del concepto de una determinada autorización al uso de la fuerza coercitiva, queda igualmente sin fundamentar el presunto primer principio del derecho natural. Se supone que este principio ya ha de estar en vigor en la moral, si bien limitado por la condición de que falte una obligación de conciencia tanto a tolerar la fuerza coercitiva, como a emplearla. Pero, que este principio esté necesariamente en vigor en el derecho natural, está, según REINHOLD, suficientemente fundamentado por el hecho de que en el derecho natural, como algo estrictamente externo, sólo tiene relevancia la fuerza coercitiva (cfr. ZIFF, 36). Tanto este fundamento conceptual, como la restricción del derecho natural al ámbito de la réplica mediante el empleo de la fuerza coercitiva contra otros, resultan insatisfactorios. Esta fundamentación no admitiría, en el ámbito del derecho natural, ni obligaciones jurídicas frente a sí mismo ${ }^{39}$, ni un principio como el postulado jurídico kantiano de la razón práctica ${ }^{40}$.

El desarrollo posterior del concepto de la deducción relativa del derecho no supera estas carencias. Cabe destacar en este sentido el modo de desarrollo llevado a cabo por K. H. HEYDENREICH ${ }^{41}$. Dicho modo de desarrollo consistía, fundamentalmente, en que la obligación del otro a no compelerme por la fuerza se completaba con la obligación de tener que tolerar el uso de la fuerza, que llevo a cabo contra su compulsión. Con ello se acentuaba, mejor que hasta entonces, el carácter de una autorización jurídica, así como la reciprocidad entre la autorización del uno (así como la de un derecho subjetivo) y la obligación jurídica de otros de respetar los derechos subjetivos existentes (incluidas las autorizaciones). Pero, ni se trataba el problema de la extensión del derecho natural en su totalidad, ni el imperativo categórico de la moralidad se hacía comprensible, como razón suficiente — junto a la consciencia de dicho imperativo-, para un derecho natural necesariamente existente. Hay que tener cuenta, además, que las objeciones aducidas contra la argumentación de HAENSEL no quedan debilitadas por el hecho de que la perspectiva de la auto-obligación interna, por medio del imperativo categórico de la moralidad, resulte duplicada a causa de una tal perspectiva en el otro; el otro no resulta obligado por mi máxima moral a no impedir la acción que resulta de aquélla. Solamente como consecuencia de su culpa moral, sin más, y a partir

9 Cfr. I. Kant, «MS» $(240$ und 246,2$)$.

40 Ibid., Metaphysische Anfangsgründe der Rechtslehre, $\$ 2$.

${ }^{41}$ K. H. HeYdenReich, System des Naturrechts nach kritischen Prinzipien, Zwei Teile, Leipzig, 17941795. 
de una máxima moral para actuar, no estoy autorizado desde el punto de vista jurídico a emplear frente a él la fuerza coercitiva (en el ámbito de la acción a partir de dicha máxima), ni él jurídicamente obligado a tolerar dicha fuerza coercitiva. Una tal vía directa, desde la reciprocidad de las perspectivas de la auto-obligación moral interna, en el uno y en el otro, a la reciprocidad de derechos subjetivos (internos o externos) de unos y obligaciones jurídicas de otros, no existe. Más bien, habría que reflexionar acerca de cómo desde la muy abstracta reciprocidad de la auto-obligación interna de varias personas, bajo el ámbito del imperativo categórico de la moralidad, se llega a la mucho más compleja (en cuanto a densidad y riqueza de contenido) reciprocidad de derechos subjetivos y obligaciones jurídicas, bajo el ámbito de normas jurídicas. Esto, en el marco del concepto de una deducción relativa del derecho a partir del imperativo categórico de la moralidad, no es posible.

2.1: El fiasco de los intentos de los que hemos tratado hace inverosímil que una fundamentación jurídica se pueda llevar a cabo recurriendo tan sólo al imperativo categórico de la moralidad y su efecto en mí, o, en caso necesario, en otros. Si no se quiere perder cualquier esperanza de una convincente fundamentación del derecho y de su necesidad, aferrándose al imperativo categórico de la moralidad como principio supremo de la doctrina de la moral, habrá que tomar en consideración otras premisas acerca de dicho imperativo, además de aquellas que ya están contenidas en mi consciencia, o en la de otros. Esto, además de la consciencia de la aplicación del imperativo a cuestiones relativas a decisiones del arbitrio. Parece que fue P. J. A. FeUERBACH el primero que en 1795 ya adoptó este planteamiento ${ }^{42}$. Los errores de quienes incluso con posterioridad todavía pensaban en los esquemas de FEUERBACH, podrían haberle valido como confirmación de su búsqueda de una nueva fundamentación. En cualquier caso, FeUERBACH llevó a cabo este empeño con poco entusiasmo. FeUERBACH tampoco entendía el derecho como conjunto de normas para las que es posible una legislación externa, sino como conjunto de derechos subjetivos de seres imputables y libres. Como razón adicional, para el derecho entendido de este modo, asumió una «capacidad de generar derecho separada de la capacidad de la razón generadora de obligaciones» ${ }^{43}$. A partir de esta capacidad para generar derecho, y siempre que se deje fundamentar de modo convincente, se puede justificar, para el derecho, una predisposición distinta a la exigida para el imperativo categórico de la moralidad. Para fundamentar la consideración de una tal capacidad de generar derecho, FEUERBACH se retrotrajo a una concepción formal de la razón (y de la razón práctica) que no se alejaba demasiado de los planteamientos (supuestamente de conformidad con KANT) de aquellos primeros representantes de una deducción del derecho, directamente, a partir del carácter imperativo que tiene en mí el imperativo categórico. La forma de la razón es, según FEUERBACH, unidad sistemática, que en el supuesto de la razón práctica abarca a la libertad. Con ayuda de dicha forma se daría la razón práctica a sí misma, en primer lugar, obligaciones para la voluntad y se pondría a sí misma un fin (ético) supremo. La razón encontraría su realización hacia este fin supremo, y, a su vez, se introduciría unidad y armonía en los muchos fines disarmónicos (tanto del sujeto individual tomado

${ }_{42}$ P. J. A. Feuerbach, «Versuch über den Begriff des Rechts», en F. I. Niethammer (Hrsg.), Philosophisches Journal, 2. Bandes, zweites Heft, Neustrelitz, 1795, 138-162.

${ }_{43}$ Ibid., 158. 
en sí mismo, como de un sujeto en comunidad con los demás). A partir de ahora, ya se intuye como sigue: la realización presupondría condiciones, sin cuyo cumplimiento la razón formal (en general o, por lo menos, en su aplicación extensiva y libre) sería imposible. De ahí que la razón tendría que sancionar dichas condiciones, esto es, declararlas inviolables — como enlazadas a la ley moral—, y determinar la libertad del sujeto en el sentido de que las condiciones pudieran ser cumplidas de cualquier modo, esto es, incluso empleando la fuerza coercitiva contra seres racionales. Esta sanción por medio de la razón «por razón de la Ley» sería el fundamento del derecho (entendido como pretensión subjetiva) y el medio, en el cual las acciones del arbitrio que uno lleva a cabo se elevarían al rango de acciones jurídicas.

No resulta difícil detectar los puntos débiles de esta argumentación. El pretendido recurso a un carácter formal de la razón en general es pura fachada. Inmediatamente, en el segundo paso, desemboca la reflexión, de nuevo, en una interpretación ética (que introduce el principio práctico supremo) de la ley moral. Pero, si la razón pura práctica es de verdad autónoma en el legislar y el auto-obligarse internamente, no puede depender, para «el alcance del fin supremo», de la imposición de condiciones que constituyan derechos subjetivos y acciones jurídicas distintos de la autodeterminación interior de la libertad. Asumir la existencia de una capacidad de producir derechos separada carecería, por lo tanto, de fundamento. Si, por el contrario, se interpretase que la razón pura práctica no es de verdad autónoma, se abandonaría el terreno de la filosofía kantiana. Además, sería del todo incomprensible que las condiciones consistentes en derechos subjetivos — aparentemente imprescindibles para la realización de la forma de la razón—, produzcan su efecto en dirección hacia una unidad sistemática que es el fin moral supremo, bajo el imperativo categórico. La imposición de las condiciones con carácter necesario «por la ley moral» hace que el derecho también se convierta en una empresa al servicio de la moralidad regulada por normas éticas, como ya venía sucediendo con HuFELAND. Las consecuencias tan graves, como antikantianas, de una tal funcionalización del derecho se hicieron notar de forma cada vez más clara en los neokantianos, cuyas posiciones filosófico-jurídicas se gestan en el ámbito de esta concepción ${ }^{44}$. FEUERBACH hizo bien en buscar, para la necesidad del derecho, un fundamento adicional al «factum de la razón» — que es la consciencia de la norma fundamental de la razón pura práctica ${ }^{45}$ - en nuestra libertad ${ }^{46}$. Este fundamento adicional es un fundamento objetivo a partir del cual, al final, también se puede desarrollar nuestra «capacidad para obligar a otros» y, con ello, el concepto de derecho subjetivo que puede hacerse valer frente otros, y que, al amparo de los correspondientes imperativos

${ }^{44}$ No es ninguna casualidad, sino que tiene su fundamento en el ámbito de un derecho funcionalizado al servicio de fines éticos, que algunos de los filósofos del derecho neokantianos (así como neohegelianos) suscribieran ideas populistas (e incluso ideas nazis) en la primera mitad del siglo Xx cuando éstas estaban en boga, puesto que los objetivos y prioridades colectivas no sólo resultan bastante vagos en el ámbito de sus objetivos parciales, cuando el concepto de aquello a lo que se atribuyen queda en sí mismo indeterminado, como es el caso en el supuesto de un fin supremo, sino que se desplazan con facilidad. Pero, si es al Estado y a sus poderes políticos a quienes se encomienda la funcionalización del derecho hacia objetivos éticos, se puede imaginar con facilidad cual es la tendencia política que se va a imponer en el mencionado desplazamiento de objetivos y prioridades colectivas.

${ }^{45}$ Vid. «KpV», 55 (vid. nota 8).

46 «De la que proceden todas las normas morales, por lo tanto también todos los derechos y obligaciones»; $; C f r$. «MS» $(239,2)$ ! 
(que generan obligaciones jurídicas), ha de hacerse valer necesariamente ${ }^{47}$. Pero, en la medida en que FEUERBACH cree encontrar el fundamento en una «sanción por medio de la razón para la Ley moral», lo estropea todo: no sólo su «intento», sino también la doctrina kantiana que le sirve de presupuesto, esto es, la doctrina de la autonomía de la razón pura práctica y su norma fundamental. Si no fuera posible añadir al imperativo categórico de la moralidad otro fundamento al que pretende FEUERBACH, para la necesidad del derecho, se haría mejor en renunciar definitivamente a cualquier esfuerzo, para la fundamentación del derecho, bajo el presupuesto del imperativo categórico de la moralidad.

Poco después de Feuerbach, desechó Fichte todos los intentos de una fundamentación del derecho a partir del imperativo categórico de la moralidad ${ }^{48}$. De modo distinto a como lo hizo en 1793, también quería FICHTE deducir el concepto del derecho y su aplicabilidad recurriendo a una forma fundamental de la razón pura (op. cit., 53). Pero de modo más consecuente que FEUERBACH independizó su deducción de toda moral y su norma, esto es, no se valió del imperativo categórico de la moralidad, ni de un fin moral supremo. La deducción abandonó, sin compromiso, el planteamiento para la fundamentación de 1793 (cfr. 1.1.2), que le había llevado a la negación de cualquier obligatoriedad del derecho, así como su necesidad con carácter anterior al arbitrio. Ahora se trata de justificar la pretensión de que la «relación jurídica» entre seres racionales (en la medida en que cada uno de ellos limita su libertad «a través del concepto de la posibilidad de la libertad del otro») ${ }^{49}$ es necesaria, como condición de la autoconsciencia de cada uno, y que, de acuerdo con ello, existe una norma jurídica que ordena a cada uno la limitación de su libertad (89). Sin embargo, el planteamiento de 1793 también habría de encontrar su lugar y su concreción en este nuevo marco ${ }^{50}$. El derecho que uno tiene y ejercita se apoya, según FICHTE, en el arbitrio común dentro de un espacio permitido. Este espacio es abierto expresamente por medio de una norma, aunque, evidentemente, la norma que así se delimita y determina no sea la que se expresa en el imperativo categórico de la moralidad, sino la norma jurídica. Como modelo le sirvió una indicación de KANT, según la cual, una norma permisiva puede ser pensada sin contradicciones. La condición para esto es, según dicha indicación, que no se derogue una obligación precedente como consecuencia «de andar a tientas en el ámbito de los supuestos que se presentan» y de admitir excepciones para uno u otro caso, sino que la condición bajo la que existe una permisión (de hacer o de no hacer) se introduzca «en la fórmula de la norma prohibitiva» ( ${ }_{\complement} \mathrm{O}$ incluso en la de la ley imperativa?) ${ }^{51}$. De ahí que para FICHTE el derecho ya no sea lo «meramente» permitido (aunque sea en virtud de una lex), sino aquello que, al amparo de la producción legislativa de carácter obligatorio de la razón autónoma (aunque distinto del imperativo categórico de la moralidad), resulta ordenado o prohibido. Pero que ade-

47 Cfr. $(236,4$ y ss.; 237,4; 239,2).

48 J. G. FicHTE, «Grundlage des Naturrechts», Jena und Leipzig, 1796, citado según I. H. FiCHTE, Gesamtausgabe der Werke (1834-46), Bd III, 54; cfr. 10, 13.

49 Ibid., Bd III, 52.

50 Cuyo contenido, que se constituye a través de los muchos pasos de que consta la deducción, no puede ser expuesto aquí. De ahí que, en lo que sigue, deje en el tintero aquello de lo que esta deducción adolece, en cuanto a la pretensión de exactitud de las consecuencias que de ella se derivan.

51 «Zum ewigen Frieden. Ein philosophischer Entwurf», A. A. VIII, (347 y ss.). 
más, es libre, en cuanto a la acción o la omisión, en lo que se refiere a las condiciones particulares del arbitrio expresamente especificadas, a través de la autolimitación del arbitrio-común.

De este modo, puede FICHTE decir ahora cuál es la relación entre la norma jurídica y la relación jurídica, y cómo ha de aplicarse bajo esta norma el concepto del derecho que especifica la relación jurídica a supuestos concretos (89 y ss.). Con ello resulta que la norma jurídica es una ley de la libertad que, sin embargo, es completamente diferente de la ley moral que se manifiesta en el imperativo categórico de la moralidad. De tal modo que ni su fundamentación, ni el desarrollo sistemático de sus especificaciones pertenecen a la doctrina de la moral. Esta libertad, que es ley dada a sí misma, no es la libertad práctica de la autonomía moral, sino una libertad teórica — del mero enjuiciar y pensar en relación a lo que, para un ser racional que se encuentra con otros en una esfera común de producción de efectos, es necesario como condición de su autoconsciencia en coincidencia consigo mismo- . Los imperativos que resultan de esta ley para tales seres racionales, son, de acuerdo con ello, meramente hipotéticos. Esto es, reglas tecnico-prácticas que no fundamentan obligaciones (es decir, necesidades incondicionales de actuar), sino solamente lo que para el arbitrio de una razón práctica condicionada por los sentidos es posible. En concreto, dichas reglas fundamentan lo que, al amparo de la norma jurídica entendida de este modo antikantiano, distingue aquello que se puede hacer (o permitido) de lo que no se puede hacer (o no permitido). De este modo se anticipa aquí la tesis de EBBINGHAUS de la independencia (cfr. 1.1.1). Eso sí, al mismo tiempo se convierte al derecho en una tecnología para la regulación social, a lo que EBBINGHAUS con buen motivo no daba ningún crédito. De este modo, comienza de nuevo la reducción del derecho a una técnica de ejercicio del poder —ahora, en nombre de la libertad-. Esta técnica, apenas delimitada por un «derecho primigenio» ${ }^{52}$, previsiblemente ha de chocar, en el ámbito de la doctrina del derecho al empleo de la fuerza coercitiva ${ }^{53} \mathrm{y}$, especialmente, en el derecho Político ${ }^{54}$, con la doctrina de la libertad práctica y su ley que le salen al paso, así como con su realización. De una prevención sistemática contra colisiones entre exigencias procedentes de estos dos ámbitos de autonomía ya no cabe hablar seriamente. Pero, sobre todo, la pura coacción práctica del arbitrio y la indicación técnico-práctica a éste, al amparo de una presunta ley jurídica de la libertad (meramente teórica), están completamente separados. Tan es así, que no se puede, a partir de la consciencia del imperativo categórico de la moralidad y de la libertad que en ello se presupone, determinar para el jus naturae un lugar «en la filosofía práctica a partir de principios». Pero es que ni siquiera es posible desarrollar la determinación «del supremo principio-distintivo», para los principios éticos y jurídicos.

Que, precisamente, de esto habría de tratarse, es lo que, siendo muy de agradecer, M. BAUM —en su etapa más joven-inculcó a sus lectores ${ }^{55}$. Sin embargo, lo que aduce BAUM para el fundamento de la división de todas las leyes de la libertad en éticas

52 S\$ $9-12$.

53 SS $13-15$

54 SS $17-21$.

55 M. BAuM, «Recht und Ethik in Kants praktischer Philosophie», en J. STOLZENBERG (Hrsg.), Kant und die Gegenwart, Berlin, 2006. 
y jurídicas sigue siendo decepcionante. La diferenciación de principios éticos y principios jurídicos tiene lugar, según BAUM, por medio de dos especificaciones distintas del concepto de actuar según una máxima. Esto es, introduciendo dos expresiones especificadoras, para la expresión «actuar según una máxima que...» en la fórmula del imperativo categórico de la moralidad. Pero, después de todo lo hasta ahora discutido, va de suyo que la posibilidad de una tal especificación no suministraría un fundamento para la necesidad del derecho. También va de suyo que dicha especificación de la determinación del arbitrio exigible, para la acción al amparo de normas jurídicas, no es alcanzable según una determinada máxima, puesto que aquélla no exige especificación de la acción según una máxima, sino abstracción de la máxima.

2.2: ¿No resulta más aconsejable, tras tantos intentos fallidos, abandonar el presupuesto de que el imperativo categórico de la moralidad sea el principio supremo de toda la doctrina de la moral (incluyendo al derecho y al presunto derecho natural) y, en lugar de ello, afirmar un imperativo más alto que no imponga una determinada forma de máxima, para, por lo menos, darse con ello la oportunidad de llegar a una clara delimitación entre ética y derecho, así como a una comprensión de la necesidad del derecho? Este intento desesperado es el que, desde hace algunos años, recomienda O. HÖFFE ${ }^{56}$. Resulta evidente que el planteamiento de HÖFFE rebasa el tema de este trabajo $^{57}$, y que no puede apoyarse en los escritos de KANT para la fundamentación de una filosofía de la moral, ni en la Metafísica de las Costumbres. Pero también sería fácil mostrar que no consigue su objetivo, porque tiene que quedar en deuda en cuanto a la legitimación del presunto principio supremo, y porque en su contenido junto a las condiciones de su aplicación, tampoco es posible encontrar el principio de distinción por el que se busca. Sólo es posible llevar a cabo con éxito la búsqueda de un fundamento epistemológico y ontológico, para la necesidad del derecho, en el marco de una filosofía práctica concebida de modo kantiano, si se agota (mejor de lo que lo hacen los mencionados autores) el potencial argumentativo que contiene el eslabón anterior a la mencionada división de los intentos de fundamentación del derecho, necesariamente objetos de discusión.

\section{ESBOZOS DE UNA NUEVA RESPUESTA}

\subsection{Las enseñanzas de lo que hasta ahora se ha venido haciendo}

¿Cuáles son los estímulos positivos que se desprenden de los intentos criticados, y qué habría que añadirles como consecuencia de la experiencia aprendida?

1. Para la comprensión de la necesidad del derecho, necesitamos, en aras de evitar el fracaso, algo más que la consciencia del imperativo categórico de la moralidad.

56 O. HÖFFE, «Der Kategorische Imperativ als Grundbegriff einer normativen Rechts- und Staatsphilosophie», en R. LÖW (Hrg.), Oikeiosis. Festschrift für Robert Spaemann, Weinheim, 1987, 87-100. «Kategorische Rechtsprinzipien. Ein Kontrapunkt der Moderne», Frankfurt am Main, 1990. I. KaNT, «Metaphysische Anfangsgründe der Rechtslehre» (Reibe Klassiker auslegen, hrsg. V. O. HöFFE, Bd. 19), Berlin, 1999, 1-18, 41-62. «Königliche Völker», Zu Kants Kosmopolitischer Rechts- und Friedenstheorie, Frankfurt am Main, 2001, 105-160.

57 ¡Cfr. el título y la primera frase! 
Pero la consciencia de la razón práctica que nosotros somos también va más allá de este «factum de la consciencia» ${ }^{58}$ en dos direcciones: (a) Registramos en nosotros este factum y, a partir de éste, además, una consciencia de nuestra libertad positivamente determinada. Y esto, como la autonomía que $\operatorname{somos}^{59}$ en tanto que arbitrio, «capacidad de la razón pura de ser práctica para sí misma ${ }^{60}$, y voluntad pura — sea en el ámbito de la auto-obligación interna o externa-. Por otra parte, con la compleja consciencia de nuestra libertad, también tenemos una consciencia del imperativo categórico de la moralidad. La libertad y la norma fundamental de la razón pura práctica se refieren, recíprocamente, la una a la otra ${ }^{61}$. (b) Pero tenemos esta doble consciencia que se alza inmediatamente con la norma moral «tan pronto como concebimos máximas de la voluntad» ${ }^{62}$. Esto es - visto desde nuestra razón práctica condicionada por los sentidos y su desarrollo-, en el lugar del tránsito desde la autoconsciencia de tal razón, hacia el de la razón pura práctica y su causalidad inteligible. Este tránsito tiene lugar y se anula, una y otra vez. Solamente a través de la reflexión acerca de aquella autoconsciencia, podemos dar cuenta de los dos «puntos de vista» o disposiciones que se requieren para la comprensión de la necesidad del derecho. Tenemos que pensar de qué manera están integradas estas disposiciones en la compleja autoconsciencia práctica que viene dada con el factum de la razón, y cómo la Crítica de la Razón Práctica kantiana nos enseña a pensar «el tránsito desde principios del todo prácticos hacia los de la moral» ${ }^{63}$. Si es que se encuentra en algún lugar, es aquí donde cabe intuir que está la clave para la solución a nuestro problema, en el marco de las posibilidades esbozadas $(2,2.1)$. Para intentar hacer de esta intuición algo más que lo hecho hasta ahora, deberíamos, por tanto, dirigirnos hacia la doctrina del concepto de un objeto de la razón práctica (en su determinación como bueno o malo) ${ }^{64}$. Un papel central juegan en ello las categorías kantianas de la libertad, que, al igual que su contexto, no habían sido tenidas en cuenta.

2. Como indicio importante que prepara para las perspectivas que van unidas a esta tarea interpretativa, hay que tomar como referencia la relación, puesta de relieve por M. BAUM, entre las declaraciones programáticas kantianas acerca del lugar del derecho natural en la filosofía práctica, y un principio distintivo supremo para principios éticos y jurídicos. Según dicha relación, la libertad ha de ser pensada como fundamento de todas las leyes que de ella resultan, y la razón pura práctica como su autonomía. Esto en lugar de que a la libertad se la tome simplemente como presupuesto para la voluntad y la actuación con arreglo al arbitrio, o a la razón pura práctica, como hace FICHTE, es dividida, a su vez, en una razón moral y una razón técnico-práctica, en el fondo teórica. Para valorar debidamente este planteamiento hay que mostrar, en primer lugar, cómo y en qué medida, en el tránsito desde la autoconsciencia de la razón condicionada por los sentidos, hacia la razón pura práctica, la norma fundamental juega su papel, para la determinación del objeto de dicha razón pura práctica bajo todas y

\footnotetext{
$58 \ll \mathrm{KpV} », 56$.

$59 \ll M S »(214)$.

$60 \ll \mathrm{KpV} \gg, 156$.

$61 \ll \mathrm{KpV} \gg, 52,3$.

$62 \ll \mathrm{KpV} », 53$.

$63 \ll \mathrm{KpV} », 118$.

64 «pV», 100, 2 y ss.
} 
cada una de las categorías de la libertad. Este papel se pone de manifiesto en el imperativo categórico de la moralidad. En segundo lugar, hay que mostrar, necesariamente, la existencia de un principio permisivo y, en simetría con ello, una norma obligatoria, exclusivamente, para acciones externas procedentes del arbitrio. Estas acciones externas son, al mismo tiempo, tangentes al arbitrio ajeno, y con respecto a las cuales uno tiene un derecho de llevarlas a cabo o de omitirlas, mientras que cualquier otro —en estricta reciprocidad — tiene la obligación correspondiente de no impedir dicha acción y de permitir su omisión. Por la dualidad de tipos de leyes obligatorias, pero prácticas en toda su extensión ( $y$, para las que existe una legislación interna y externa que, por lo menos, se le pueda sumar a las normas del segundo tipo) no pasa ningún camino, ni tampoco un fundamento normativo, para el mencionado principio permisivo. Que el imperativo categórico de la moralidad no divida todas las opciones del arbitrio existentes en ordenadas y prohibidas, sino que, junto a ellas, también deje opciones que resultan — con respecto a lo que está ordenado o prohibido (por aquél)—indiferentes, no puede, como tal fundamento, ser suficiente.

3. Como consecuencia de ello, resulta inevitable preguntar por la necesidad de una ley permisiva y sopesar si no se está haciendo ya uso de ésta, como forma de completar a la norma obligatoria, y su obligatoriedad, que se pone de manifiesto en el imperativo categórico de la moralidad (por medio de la auto-obligación moral interna). KANT no se pronunció expresamente sobre la necesidad de una tal lex permissiva. Pero en el esbozo Hacia la Paz Perpetua, KanT dejó claro de que modo puede ser pensada sin contradicciones una tal lex, adicionalmente y junto a una ley obligatoria, si aquélla se proyecta sobre un estado de cosas distinto de aquel al que se refiere esta ley obligatoria. También dejó claro que esto es posible, incluso, si la lex permissiva formula una condición restrictiva de su carácter obligatorio ${ }^{65}$. Unos años después, llamaba KANT la atención acerca de la posibilidad de preguntar, con razón, si existe una tal lex. Si, junto a una ley imperativa, así como prohibitiva, que fija lo indiferentemente permitido, todavía resulta necesaria la lex permissiva. Y, con respecto a que, lo permitido al amparo de ésta ya no lo sería indiferentemente ${ }^{66}$. De ahí, que haya que reflexionar acerca de si todo ello no tiene consecuencias de mucho más calado en relación al buscado principio distintivo, y a la cuestionable necesidad del derecho. Hasta ahora y hasta donde puedo observar, dichas consecuencias no han sido tomadas en consideración. Creo que se puede mostrar cómo esta lex permissiva proporciona la que, habiendo de intuirse en la doctrina de las categorías de la libertad, es la clave para la solución a nuestro problema.

\subsection{Lo que se deduciría de una suprema ley permisiva}

La enorme relevancia de una ley permisiva que aparece junto a la ley obligatoria, la cual, a su vez, entra en vigor por medio del imperativo categórico de la moralidad, es fácil de ver. La autonomía de la razón pura práctica produce, adicionalmente a la mencionada ley obligatoria, una ley permisiva (para todo lo que bajo la ley obligatoria no está prohibido - o incluso, aunque sólo sea para una parte de lo que no está prohi-

\footnotetext{
${ }^{6}$ A. A. VIII, (347 y ss.).

$66 \ll \mathrm{MS}$ (223).
} 
bido)—. Esta ley permisiva ha de asegurar — de modo simétrico al carácter vinculante de la legislación obligatoria - para todo lo permitido de este modo, que se pueda hacer uso de la permisión, esto es, que ésta no se eche a perder en el ámbito efectual de las leyes de la libertad, como consecuencia de impedimentos que influyan en el arbitrio. Con la presupuesta libertad (en el sentido mencionado), se supone que cada sujeto de voluntad es, en el uso interno de su arbitrio, dueño de sí mismo, y que, únicamente, las modificaciones causadas por sucesos naturales sobre las opciones puestas en su arbitrio quedan al margen del señorío de la libertad. De este modo, restricciones relevantes referidas al uso de la permisión normativa sólo pueden afectar a la acción externa, en el ámbito de la (recíproca) relación de una persona con el estado en que se encuentre el arbitrio de otra. Estas restricciones han de quedar excluidas por medio de una ley (de carácter obligatorio) reguladora de la libertad, que posibilite a quien actúa hacer uso de la permisión que le viene atribuida por dicha ley ${ }^{67}$. Ab esse (aquí: estar-permitido en virtud de una ley), ad posse (aquí: poder-hacer lo permitido, porque está autorizado y protegido por la ley) valet consequentia. Aquí la posibilidad no resulta problemática del lado del que actúa, sino sólo del lado de los otros, con los que quien actúa se encuentra en relación de mutua influenciabilidad como consecuencia de la acción externa. De ahí que esta ley (como una que tiene que diferenciarse tanto de la ley obligatoria interna, como de la ley permisiva) haya de referirse exclusivamente a la regulación de tales relaciones de arbitrio externas. Esto es, una ley que no regula las determinaciones internas de la causalidad de la razón práctica (ni con ello máximas), sino solamente la acción externa con arreglo al arbitrio, en la medida en que quien actúa se encuentra en aquella relación de reciprocidad. Con ello, por tanto, tendríamos una ley jurídica y su necesidad - incluyendo además una explicación sobre la particular modalidad de esta última- Se trataría de una necesidad del tipo de una implicación pura práctica (por lo tanto, autodeterminada y que se determina conceptualmente a sí misma). Esta necesidad estaría, además, contenida en el concepto de una ley (de carácter permisivo) demostrada, si la razón pura práctica en su actividad legislativa coincidiera consigo misma, o, si quisiera constituirse en una unidad como voluntad racional pura.

Tal y como, en un supuesto más sencillo, se puede comprobar, KANT vislumbró por completo la relación cuasi-analítica entre una ley permisiva que explícitamente autoriza a hacer uso de una determinada opción puesta en el arbitrio como permitida (y posibilitada), y una norma obligatoria, en virtud de la cual, ha de concederse a otros la posibilidad de hacer lo que, de este modo, resulta permitido. En el $\$ 2$ de la Doctrina del derecho, «el postulado jurídico de la razón práctica» (según el cual, me resulta jurídicamente posible tener como mío todo objeto externo puesto en mi arbitrio) recibe la denominación de una «ley permisiva (lex permissiva) de la razón práctica». Y esto, porque nos «otorga la facultad [...] de imponer a todos los demás una obligación, que de otro modo no tendrían, de abstenerse del uso de determinados objetos puestos en nuestro arbitrio, por el hecho de haber sido los primeros en adquirir la posesión de los mismos» (247). Sin embargo, en el $\$ 6$ se afirma, apelando al mencionado postulado jurídico, en concreto citándolo, que «es una obligación jurídica actuar con respecto

${ }^{67}$ Del mismo modo que en el Código de la Circulación corresponde a la permisión de un cambio de carril (la cual, por ejemplo, está expresada en una flecha de color blanco sobre fondo azul, apuntando hacia la izquierda) el mandato, para otros que ya se encuentran en el carril en cuestión, de dejar incorporarse a este otro carril a aquel que se dispone a hacer uso de la permisión que le ha sido concedida. 
a otros de tal modo que lo externo (utilizable) también pueda llegar a ser lo suyo de cualquier otro» (252). En este punto hay que mencionar el problema de la relación entre la ley permisiva universal, la cual forma parte de la constitución del objeto de una razón pura práctica, y la ley jurídica universal (como norma jurídica suprema). En este caso, la complicación de dicha relación tan sólo consiste en que aquí (con el tránsito desde la permisión que cada uno tiene al amparo de esta ley permisiva, hacia la obligación respectiva para todos los demás), primero, tiene lugar una restricción de la acción externa, esto es, del arbitrio en su uso externo (en tanto que éste pueda tener influencia en el uso del arbitrio de otros). Mientras que la permisión que formula el postulado jurídico de la razón práctica, ya ha hecho esta restricción con carácter anterior. Sin embargo, la dificultad que va unida a esta restricción es superada, por medio de un paso que está, asimismo, contenido analíticamente en el concepto realizado de la consecuente legislación de la razón pura práctica ${ }^{68}$.

De este modo, el derecho no existiría con carácter necesario, solamente, para aquel que primero se somete a la obligatoriedad interna de la ley moral, en tanto que aplica el imperativo categórico de la moralidad a la formación y observancia de sus máximas. Más bien, existiría el derecho con anterioridad, para quien registra en su fuero interno el «factum de la consciencia». Esto es, quien registra que por medio de este imperativo está exhortado a la moralidad y que, como consecuencia ello, llega a la consciencia de su libertad, pero que sólo hace uso de la permisión normativa que vaya unida a una tal producción legislativa, en la medida en que esto se refiera a un tipo de acción externa. Según KANT, ningún ser racional puede evitar hacer uso de la libertad, para esto último, en cuanto trate de esbozar cualesquiera máximas. Pero, el ser racional en cuestión, en este estadio anterior al desarrollo de su razón práctica, no responde ni jurídica ni moral ni éticamente ¿No habría de hacerse uso, junto con la libertad, de una permisión normativa? En cualquier caso, comprenderíamos a partir del carácter necesario del derecho, explicado de este modo, que sus normas (referidas exclusivamente a la conducta con arreglo al arbitrio externo) tienen como destinatarios a todos los seres racionales finitos que, por lo menos, se encuentren, con otro, en la relación de aquella posible influencia recíproca ${ }^{69}$, desde el estadio de desarrollo señalado.

${ }^{68}$ La razón práctica que se encuentra bajo el imperativo categórico de la moralidad siempre es pensada, en cuanto a un objeto de la razón pura práctica y lo permitido en virtud de una ley, como capacidad de alguien que en el uso interno de su arbitrio es dueño de sí mismo, y que en el uso externo de dicho arbitrio sólo puede ser impedido por otros (contra su propia voluntad), pero nunca por sí mismo. Por lo tanto, la relación analítica que en la legislación práctica puede darse entre aquello que una ley permisiva concede a alguien, y una ley obligatoria que respectivamente restringe (ordenando o prohibiendo) en otros el uso de su arbitrio externo, sólo puede recubrir una parte de toda la extensión de lo que al amparo de la ley permisiva resulta explícitamente permitido: Aquella parte que se deja obstaculizar por la acción externa de otros, precisamente porque dicha parte constituye acción externa y el correspondiente uso del arbitrio por una persona — pero de tal modo que ésta se acoge con aquélla al marco de la misma ley, esto es, cumple por su parte la condición de hacer compatible su libertad con la de cada uno de los otros-. Justo esta parte de las opciones que se encuentran en el arbitrio de cada uno constituye la extensión de lo que, en el sentido del principio general kantiano, es una acción (o una omisión) con arreglo a derecho ( $c f r$. $\$ C). Pero en una y la misma producción legislativa de tipo práctico, la relación de este principio con aquella ley obligatoria referida al uso externo del arbitrio hace a los derechos y obligaciones que existen en la relación recíproca entre distintas personas estrictamente simétricos, al igual que los dos principios (permisivo y obligatorio), de tal modo que lo mejor sea que el tratamiento de estos tenga lugar en un único parágrafo.

${ }_{69}$ Claro que no cada uno con cada uno, pero sí cada uno con al menos otro que a su vez se encuentre en el plexo de la posible influenciabilidad, como mínimo, con otro. 


\subsection{Perspectivas de conocimiento adicionales bajo el presupuesto de una suprema ley permisiva}

Echemos aquí un vistazo a las posibilidades que tiene KANT de superar los problemas mencionados al principio. KANT, además, plantea, junto al esclarecimiento acerca de la necesidad del derecho, una convincente fundamentación del derecho.

1. Con la necesidad del derecho ${ }^{70}$ y la información acerca del carácter de dicha necesidad, también queda resuelta la cuestión acerca de para quién, y, en determinadas circunstancias, para qué tipo de disposición en la que se encuentre la persona en cuestión, es el derecho un conjunto de leyes con producción legislativa de una especie particular. Otro tanto, por lo que se refiere a la cuestión de en qué medida son estas leyes de la libertad, y por qué se aplican exclusivamente al arbitrio en su uso externo y recíproca relación de su posible influencia sobre el arbitrio de otros. Es más: con la precisión acerca de la necesidad del derecho, se resuelve la cuestión de por qué, a partir del correspondiente concepto del derecho y su aplicabilidad, se deduce en la formulación kantiana un correspondiente principio de permisión jurídica y —de modo simétrico- una norma jurídica general. La cual, al menos en cuanto obligación moral, posee carácter imperativo, pero también obliga por medio de una legislación externa. Esto último, siempre que una tal legislación externa sea posible y, de uno u otro modo, efectiva. Que esta legislación externa, en el ámbito efectual del empleo de la fuerza coercitiva externa, es jurídicamente posible y efectiva, al menos en el contexto de la recíproca efectualidad de sujetos de derecho privado que hacen valer su derecho subjetivo contra otros de este modo, resulta de un sencillo argumento. Se trata de un argumento a favor de la permisión de movilizar contra otros el uso de la fuerza coercitiva externa, para hacer valer pretensiones jurídicas (procedentes de derechos subjetivos internos o externos), pero sin vulnerar ni su dignidad ni su autoestima $(\mathbb{D})$. Cuando aquí se habla de legislación externa jurídicamente posible y efectiva, es en el sentido del concepto del derecho que se ha definido, así como del principio general del derecho y de la norma jurídica.

Si la asunción de una ley permisiva es acertada y se deja fundamentar, el modo de proceder de KANT al comienzo de los primeros fundamentos metafísicos de una doctrina del derecho, donde inmediatamente se organiza todo en torno al concepto del conjunto de leyes, para las que es posible una legislación externa $(\mathbb{A})$, también resultaría grosso modo legitimado. A continuación, da KANT, para este concepto, una definición real $(\mathbb{B})$ referida a toda la extensión de su aplicación, mediante la obligación moral que, en cuanto a su objeto, existe en todo caso. Igualmente suministra la formulación de un principio y norma jurídica general correspondiente a aquella definición $(\mathbb{C})$. Finalmente, incluso, se contempla la posibilidad, para toda acción externa (la única relevante) con arreglo a esta ley (y a las especiales normas jurídicas que eventualmente se encuentren por debajo de aquélla), de vincular una legislación externa al concepto del uso de la fuerza coercitiva externa $(\mathbb{D})$. Y esto, sin que con ello se esté en contradicción ni con el derecho, ni con sus fundamentos conceptuales, ni con la au-

70 La necesidad, claro está, que hasta ahora sólo resulta demostrada bajo el presupuesto de una ley permisiva que se suma al imperativo categórico de la moralidad precisando su ámbito de aplicación. 
tonomía de la razón pura práctica, y sin abandonar su terreno. De este modo, la forma de proceder en los cuatro primeros parágrafos de la «Doctrina del derecho» constituye una implícita toma de postura crítica en relación a todas las doctrinas de fundamentación del derecho kantianizantes (ya vistas), que trataron esta difícil materia antes que el propio KANT, quien, en cuanto a contundencia e intensidad de penetración en la cosa misma, les supera con creces.

2. Así las cosas, ya no resulta difícil, al menos en un primer esbozo, precisar en qué consiste el supremo principio distintivo para la división de principios de la moralidad (en jurídicos y éticos). No puede consistir en otra cosa que no sea el fundamento buscado para la necesidad de la ley permisiva. La razón estriba en el hecho de que este fundamento no sólo nos va a explicar el porqué de la existencia de una ley permisiva. La cual, en coordinación con lo ordenado y prohibido por el imperativo categórico de la moralidad, determina lo permitido en virtud de dicha ley, y, además, fija su demarcación frente a lo que ya al amparo del imperativo categórico de la moralidad, en cualesquiera de los posibles sentidos lógicos acerca de lo permitido ${ }^{71}$, constituye una permisión. El mencionado fundamento, para la necesidad del derecho, también nos aclara el porqué de la existencia de principios objetivos específicos, para la determinación del arbitrio en el mero uso externo, y porqué han de ser tenidos en cuenta. Nos aclara porqué se han de distinguir aquellos principios de los de la determinación interna de la voluntad (como una determinación según el imperativo categórico de la moralidad y el acceso de fundamentos éticos), por el hecho de que ni den un motivo determinado para la acción, ni un fin que vaya más allá de la acción externa. Y, por ello, también aclara de modo específico la razón, en virtud de la cual, para la acción bajo aquellos principios objetivos, ha de segregarse la puesta en funcionamiento del libre arbitrio en la realización de opciones externas puestas en el arbitrio, de la puesta en funcionamiento interna del arbitrio. Y esto, de modo recíproco a la abstracción de la libertad interna de la externa, en la que se apoya la «Segregación de la Doctrina de la Virtud de la del derecho» ${ }^{72}$. También ha de tener lugar una primera segregación, puesto que sin abstracción de la puesta en marcha del arbitrio externo del interno no podría tener lugar la observancia de la norma jurídica. Los principios para esta primera segregación tienen que ser específicos, habida cuenta que la norma jurídica es necesariamente una legislación de tipo y contenido propio, y dichos principios han de dejar al margen tanto motivos, como fines, ya que la ley nada prevé para estos.

3. Sin embargo, en la medida de lo previsible, no se llega a una colisión entre las exigencias que, para nuestra acción, existen bajo el imperativo categórico de la moralidad y acciones previstas por la norma jurídica, como prescritas, permitidas, o prohibidas. Ello se debe a que la norma jurídica es una norma totalmente distinta de la que exclusivamente me obliga internamente. La norma jurídica es aquella norma, según la cual, el libre uso del arbitrio de cada uno, para la acción externa, puede coexistir con el de todos los demás (por lo que el arbitrio de todos se deja fusionar

${ }^{71}$ Para los tres significados compárese J. HrusCHKA, «Das deontologische Sechseck bei Gottfried Achenwall im Jahre 1767. Zur Geschichte der deontischen Grundbegriffe in der Universaljurisprudenz zwischen Suarez und Kant», en Berichte aus den Sitzungen der Joachim Jungius — Gesellschaft der Wissenschaften, Jg. 4, Heft 2, Hamburg/Göttingen, 1986.

${ }^{72} C f r$. «MS» $(406,3)$. 
en una voluntad general). Sin embargo, la norma que exclusivamente me obliga en mi fuero interno, por medio del imperativo categórico de la moralidad, no asegura en absoluto una tal compatibilidad de las puestas en funcionamiento del arbitrio de distintos sujetos en concreto (a la vista de sus distintas limitaciones en cuanto a la posible reflexión acerca de la idoneidad normativa de máximas). Ni, mucho menos aún, prescribe dicha compatibilidad. Esta norma moral contiene, en el mejor de los casos, como mucho, la idea de una unión de todos los sujetos morales en sus máximas de la voluntad. Pero, lo prohibido por la norma jurídica, o la acción prevista, no obstante su existencia bajo un tipo de legislador específico y normas de contenido específico, no es otra acción externa que la prohibida bajo el imperativo categórico de la moralidad, o la expresamente permitida por la correspondiente ley permisiva para el ámbito de la acción externa (en los distintos sentidos lógicos de la expresión «permitido», entre los que también se encuentra el sentido de «no prohibido, pero ordenado»). Bajo normas jurídicas, sólo se regula por medio de otro tipo de legislación y partiendo de una distinta disposición interna hacia la norma. Ahora bien, esto último, de tal manera que, siguiendo la regulación normativa y más allá de la observancia de estas normas generales, cada persona también pueda querer, sin colisión a través de la máxima de su voluntad y siempre que ésta satisfaga la exigencia del imperativo categórico de la moralidad, que la máxima pueda llegar a convertirse en una norma de carácter universal. Por lo menos, en una norma, en la que - aunque integrada también en el mandato de un determinado motivo moral y el de una disposición de fines éticos- entren en juego las normas procedentes de la puesta en funcionamiento de una libertad compatible para una especificación de la norma, que con la definición del concepto del derecho ya ha sido pensada en abstracto. Puesto que, además, el principio jurídico universal tiene en cuenta esta norma, junto a la relación lógica entre ésta y sus especificaciones, y la norma jurídica universal eleva a norma la limitación de la libertad que en sí misma aparece contemplada, tampoco se origina el peligro de una antinomia bajo las normas de la libertad. De esta forma tan continua, queda armonizado el contenido de la legislación jurídica con el supremo fundamento de la doctrina de la moral.

4. La armonización con el imperativo categórico de la moralidad también vale para el específico modo de obligar que puede llegar a ser atribuido a normas jurídicas (adicionalmente a la obligatoriedad moral interna), sobre la base de su legislación descentralizada y pre-positiva, esto es, por su propio carácter prescriptivo. Y es que dicho carácter prescriptivo tiene el modo de producir efectos de una auto-obligación - aunque indirecta, en cuanto a lo que resulta de las acciones de otros- y de la autonomía a través de la razón pura práctica. Ésta obliga y produce efectos en la medida en que otras personas asumen, en caso necesario, el papel de reforzar al afectado en su consideración hacia la norma, y el de obligar a su observancia con motores externos. Presupuesto de lo anterior es la ausencia —o, excesivamente débil- capacidad interna, para obligarse a sí mismo. Con ello, estas otras personas ponen en acción, en el ámbito de la percepción de un derecho subjetivo propio, un «poder de obligar a otros» a la observancia de normas jurídicas obligatorias, que, sin un tal mecanismo, carecerían de legislación externa. Si la puesta en marcha de este mecanismo tiene lugar del modo adecuado, significa que no se adelanta a esta capacidad interna, sino que la asiste en caso de carencia de fuerza de la motivación, o ausencia de predisposición a la observancia del imperativo categórico de la moralidad. Ahora bien, la puesta en 
marcha de dicho mecanismo sólo tiene lugar de modo adecuado, en la medida en que con esta forma de obligar no se perjudique ${ }^{73}$ ni el respeto a sí mismo del obligado, ni su disposición hacia la capacidad interna de obligarse. Las normas obligatorias se cumplen en la percepción de «obligaciones éticas indirectas» ${ }^{74}$ tan pronto, como, según el imperativo, la intención esté disponible. Si ley permisiva, hasta ahora tan sólo supuesta, se revelara como necesaria, existiría continuidad epistémica entre la consciencia del imperativo categórico de la moralidad y los principios de la «Doctrina del derecho» que se exponen en los parágrafos A-D. Pretender ${ }^{75}$ que un tránsito inmanente desde la Filosofía Moral hacia la Filosofía del derecho no es posible sería, por lo tanto, un desacierto.

\section{4. Últimos presupuestos para la afirmación de que existe una suprema ley permisiva}

¿Cómo puede la doctrina kantiana del concepto de un objeto de la razón pura práctica contribuir al esclarecimiento de la necesidad de una ley permisiva que acompañe al imperativo categórico de la moralidad? Y esto, en la medida en la que dicha ley permisiva complemente el contenido del mencionado imperativo, por medio de una explícita especificación normativa - hasta entonces no contenida en el mismo-. Además, la ley permisiva está, en última instancia, orientada hacia otra situación personal que aquella a la que se orienta el imperativo. El trasfondo y el núcleo de esta doctrina habrían merecido un tratamiento específico detallado ${ }^{76}$. Pero, incluso sin ello, es posible esclarecer lo necesario para este cometido. Para esto, hay que reflexionar ahora

73 Probablemente haya que añadir aquí que la puesta en funcionamiento de la capacidad de obligar a otros también ha de estar orientada a un «estado de cosas jurídico», en el que «cada uno pueda llegar a ser partícipe de su derecho». Cfr. (306).

74 Cfr. (221).

75 En contra de esto, KeRSTING, «Wohlgeordnete Freiheit», ibid., 30 y ss.

76 Referidos al capítulo kantiano del concepto de un objeto de la razón pura práctica («KpV», 100 y ss.) han sido publicados, sobre todo en los últimos 20 años, muchos artículos que han contribuido notablemente a la comprensión de las categorías de la libertad - W. L. BECK, por ejemplo, ya se había ocupado de ello, aunque de forma todavía, muy rudimentaria- (A Commentary of Kant's Critique of Practical reason, Chicago/London, 1960, Ch. IX): Cfr. R. J. Benton, «Kant's Categories of Practical Reason as Such», en Kant-Studien, 71, 1980, 181-201. G. SCHÖNRICH, «Die Kategorien der Freiheit als handlungstheoretische Elementarbegriffe», en G. Prauss (Hrsg.), Handlungstheoretische und Transzendentalphilosophie, Frankfurt am Main, 1986, 246-270. S. BobZien, «Die Kategorien der Freiheit bei Kant», en H. Oberer y G. SEel (Hrsg.): Kant. Analysen - Probleme - Kritik, Würzburg, 1988, 193-220. J. SimON, «Kategorien der Freiheit und der Natur. Zum primat des Praktischen bei Kant», en D. KOCH y K. BORT (Hrsg.): Kategorie und kategorialität. Historisch-systematische Untersuchungen zum Begriff der Kategorie im philosophischen Denken, Würzburg, 1990, 107-130. Th. KoBUSCH, «Die Kategorien der Freiheit. Stationen einer historischen Entwicklung: Pufendorf, Kant, Chalybäus», en Allg. Zeitschrift f. Philos. 15, 1990, 13-37. B. HAAs, «Die Kategorien der Freiheit», en H. OBERER (Hrsg.): kant. Analysen - Probleme - kritik, Bd III, Würzburg, 1997, 41-76. V. DIERINGER, «Was erkennt die praktische Vernunft? Zu Kants Begriff des Guten in der "Kritik der praktischen Vernunft”», en Kant-Studien, 93, 2002, 137-157. Lamentablemente, no puedo exponer aquí lo que agradezco a este trabajo preparatorio, ni las reservas que tengo en relación con algunas de sus singularidades. En lo sucesivo, intento, referido al todo, penetrar con más profundidad que hasta ahora en el fundamento y sentido que tiene el orden de las categorías de la libertad como un orden de conceptos, los cuales especifican tanto la efectualidad de la razón práctica, como su juicio. Para hacer justicia a este orden, hay que concentrarse, sobre todo, en la pregunta acerca de cómo la razón práctica, en su efectualidad y en su juicio, va desde la razón práctica condicionada por los sentidos hacia la razón pura práctica. y lo que el tránsito significa para la comprensión de las distintas categorías modales de la libertad. 
acerca de cómo la razón autónoma, por lo tanto pura práctica, a través de las categorías de su libertad, determina y materializa el objeto a estimar como bueno, en la medida en que la razón pura, en la puesta en marcha de la razón práctica, se impone en todo caso a la razón práctica condicionada por los sentidos.

1. La perspectiva en la que hay que situarse es, por lo tanto, la de la (objetiva y subjetiva) autodeterminación de la razón pura práctica como una causalidad procedente de la libertad; pero esto, en respuesta a la pregunta: «¿Qué debo hacer?». Pregunta que ceja solamente cuando se encuentra la respuesta para cada uno de los casos concretos de acciones singulares del tipo: determinadas opciones de arbitrio que yo tengo. Para ello, el imperativo categórico de la moralidad no sólo ha de ser contemplado desde el punto de vista de su carácter imperativo o prohibitivo, para la formación de sus máximas. Hay que contemplarlo, además, en su relación hacia todo lo que, en la formación de máximas o su observancia, es relevante, para la determinación de la voluntad y la decisión en el ámbito del libre arbitrio, pero que, de momento, no coadyuva al modo de efectualidad de la razón pura práctica, sino que deja actuar a la razón práctica al servicio de la sensibilidad. A ello pertenecen, (1) aparte de las máximas, las meras reglas bajo las cuales se encuentra la razón práctica condicionada por los sentidos, así como, eventualmente, otras normas, además de las que se expresan —legislandoen el imperativo categórico de la moralidad. Pero, adicionalmente a estos diversos fundamentos cuantitativos para uno, algunos, o todos los seres racionales, también forman parte, cualitativamente, (2) respecto al modo de llegar a ser determinantes para la acción, distintas reglas que han de ser subsumidas bajo aquellos fundamentos. Estos fundamentos son los necesarios tanto para, por medio de un silogismo práctico, poder llegar a las acciones $\mathrm{u}$ omisiones individuales procedentes del arbitrio, como a uno $\mathrm{u}$ otro enjuiciamiento de este resultado de la puesta en marcha de la razón. Pero esto, en relación (3) a la conclusión de la razón, para la persona que se decide y la situación en la que dicha persona se encuentra (esto es, bajo determinadas circunstancias). Dichas circunstancias, igualmente, se refieren a la posible determinación de una persona sobre la situación de otra de modo recíproco. Y esto, en tanto que la determinación recíproca sea relevante para la atribución de responsabilidad, o la propia conclusión práctica de la razón misma, esto es, para su juicio. Bajo la consideración de todo esto, ha de ser juzgado el resultado de la decisión, en la medida en que está sometido al arbitrio valorar como bueno o malo (esto es, no sólo como bien o mal). Y esto, con anterioridad a la determinación de la voluntad conducente al mencionado resultado. Según las formas lógicas de todos los juicios, la estimativa ha de realizarse no sólo bajo los mencionados aspectos de cantidad, cualidad y relación, sino también (4) en cuanto a la modalidad del objeto, esto es, según las modalidades del juicio posible/imposible, real/irreal, necesario/casual. Sin embargo, lo que esto significa, para la continuación de la fijación categorial del objeto, o sea, su estimación como bueno o malo, sólo aflora, si se toma en consideración, con más detenimiento que hasta ahora, el concepto del objeto que aquí ha de pensarse y el procedimiento para su fijación.

Un objeto de la razón práctica es, según su concepto, «representación de un objeto como una efectualidad posible que se genera por medio de la libertad» ${ }^{77}$. Es, por lo tanto, la libertad, la que en su efectualización se especifica en cuanto: (1) a la extensión

$77 \ll \mathrm{KpV} », 100$. 
de los fundamentos conforme a los cuales se efectualiza, (2) a la cualidad de la efectualización según cualesquiera reglas, bajo este o aquel fundamento, (3) a la relación que la efectualización tiene para una u otra persona, o su situación, y (4) a la modalidad, en la que, en todo caso, la efectualización de la razón práctica ha de ser determinada y enjuiciada como buena, en contraposición a su discualificación como mala. El objeto hacia el que la libertad se efectualiza de este modo, es un objeto de la razón pura práctica, cuando la libertad constituye no sólo su razón necesaria, sino también suficiente —esto es, la razón determinante de lo efectual—. Por el contrario, las categorías de la libertad, las cuales especifican la libertad, o sea, su efectualidad en los cuatro ámbitos mencionados (bajo cada dos conceptos a combinar en un tercero ${ }^{78}$ ), son, dicho en general, «modos de una única categoría» bajo aquellas que el puro entendimiento posee en la determinación teórica de su objeto de conocimiento, a saber: la de la causalidad. Pero, son modos de causalidad solamente «en la medida en que la razón determinante de las mismas estriba en la representación racional de una ley que, como ley de la libertad, la propia razón da, mostrándose por ello a priori como práctica» ${ }^{79}$. Las categorías pueden «tener lugar» en relación a sucesos en el mundo sensible que sean acciones de libre arbitrio $^{80}$, «para someter la multiplicidad de las voliciones a la unidad de una razón práctica que ordena en la norma moral, o a una voluntad pura a priori» (ibid., 115). La prestación de las categorías consiste en conducir el modo de efectualización de la razón práctica en dirección hacia la efectualización que, en su función determinante, tiene lugar en la razón pura práctica, y hacia lo efectualizado por la libertad, así como su juicio, llevándolo de este modo a buen término. Pero, como esta prestación no se lleva a cabo de modo ciego, inconsciente y sin que tenga lugar un enjuiciamiento, hay que ordenar las categorías de la libertad en su totalidad como formas de enjuiciar la efectualización «en consideración a los conceptos de lo bueno y lo malo», según los cuatro cuadrantes de la sistemática de las formas del juicio.

2. Sin embargo, para el contenido conceptual de cada una de las categorías de la libertad y su respectiva relación sistemática, ha de tomarse en consideración otra circunstancia. Ya quedó dicho (en 3. A.,1.) que la doctrina de un objeto de la razón pura práctica, en la cual las categorías de la libertad juegan su papel, no se ocupa de inmediato y exclusivamente de la razón pura práctica o simplemente del resultado de su puesta en funcionamiento, sino del tránsito desde principios prácticos hacia los principios de la moralidad. Y, con ello, también se ocupa dicha doctrina del tránsito desde la razón práctica condicionada por los sentidos hacia la razón pura. En cualquier caso, siempre que se pone en marcha la razón práctica, ha de imponerse, en primer lugar, la razón pura práctica al modo efectual de la razón práctica condicionada por los sentidos, antes de que aquélla pueda determinar y enjuiciar como buena su efectualidad, y, como bueno, su objeto en la perspectiva esbozada. Por lo tanto, en el ámbito más próximo de la perspectiva subyace una actividad de la razón práctica en general, cuya efectualidad y cuyo objeto todavía no pueden ser determinados ni en-

$78 C f r ., \ll \mathrm{KU} »($ nota LVII).

$79 \ll \mathrm{KpV} \gg, 114$.

80 «Por lo tanto, según la categorías del entendimiento, pero no en la intención de un uso teórico de las mismas, para someter a la multiplicidad de las intuiciones sensibles a una consciencia a priori» (ibid.). Para la pregunta acerca de por qué las categorías de la libertad, al contrario que las del puro entendimiento, no necesitan de la intuición, $c f r$, ibid. (116). 
juiciados como bueno o malo, sino solamente como relativos al bien, o al mal. Y, con ello, en relación a condiciones que dependen de la naturaleza y que especifican a los seres racionales, bajo las cuales algo ha de ser enjuiciado según los correspondientes principios de la razón de este modo, esto es, en relación al bien, o mal. Naturalmente que en tal enjuiciamiento también están en juego conceptos, bajo todos los cuatro puntos de vista, para las formas del juicio. Pero, cualquiera que sea su contenido más próximo, significa esto, para la razón pura práctica, que su objeto, de inmediato, es decir, antes de completar el tránsito hacia los principios de la moralidad, no puede ser determinado asertóricamente, sino tan sólo problemáticamente. Y que, mientras tanto, sus correspondientes categorías están indeterminadas no solamente con respecto a la pregunta de si algo cae bajo éstas o no, esto es, si son conceptos plenos, o no, sino también en otros varios aspectos. Sea que la multiplicidad de las voliciones siempre se encuentre para mi razón práctica, en general, pensada en principios subjetivos, los cuales son mis máximas, y que para su observancia siempre valgan cualesquiera principios prácticos objetivos — «prescripciones»— bajo las cuales me encuentro junto con algunos otros seres racionales: la pregunta de si también existen principios prácticos - tanto objetivos como subjetivos- universales, esto es, válidos para todos los seres racionales, y cuál sea su contenido, queda, en relación a las categorías de la libertad, y antes del tránsito de la razón práctica en general hacia los principios de la moralidad, totalmente abierta. Otro tanto sucede con respecto a las categorías de la cualidad: bajo cualesquiera máximas se dejan subsumir tanto reglas de ejecución de acciones (según la correspondiente máxima), como reglas de omisión. Y bajo las prescripciones concernientes a un enjuiciamiento, pueden dejarse subsumir indicaciones más específicas tanto para la ejecución, como para la omisión de acciones, de tal modo que las decisiones de libre arbitrio a las que llega la razón práctica, se pueden criticar bajo las correspondientes categorías. Pero, que la crítica de la razón no sea suspendida una y otra vez, bajo reglas adicionales para supuestos excepcionales, está sin determinar. También está por determinar, según el orden de las categorías de la libertad y antes del tránsito hacia los principios de la moralidad, si, por el contrario, tales supuestos excepcionales, bajo principios objetivos de igual fuerza, quedan excluidos precisamente porque estos principios tienen el carácter de leyes. Queda en todo caso sin determinar, si, antes de dicho tránsito bajo las categorías de la libertad, la determinación (recíproca) de una persona sobre el estado de otra, juega algún papel, para la determinación del objeto de la razón práctica y su enjuiciamiento, o si existen leyes, bajo las cuales juegue aquélla un papel constitutivo.

Solamente de las categorías de la modalidad se dice que «introducen» ${ }^{81}$ el tránsito que aquí interesa. En la segunda categoría de la modalidad ya se contempla este tránsito como ejecutado. La razón estriba en que, en el ámbito de esta categoría, las máximas, las reglas para su observancia, y las decisiones de libre arbitrio que de ello se derivan, son pensadas - bajo leyes prácticas - como obligación. Dichas decisiones de libre arbitrio, son además, separadas — como contrarias a la obligación- de las decisiones diametralmente opuestas, y, correspondientemente, enjuiciadas, a saber: unas como buenas, las otras como malas. Y, sin embargo, entre lo de este modo determinado categorialmente todavía queda espacio para adiaphora, que ni son buenos ni

$81 \ll \mathrm{KpV} », 118$. 
malos $^{82}$. Sin embargo, las categorías de la modalidad solamente introducen el tránsito, en tanto en cuanto distribuyen, con la primera de las categorías, el espacio de todo lo que, bajo la segunda, habrá de ser pensado como obligación, contrario a la obligación, o adiaphoron. Este espacio es distribuido en uno de opciones de lo «permitido», y en otro de opciones de lo «no permitido» — «pero», en primer lugar, «sólo problemáticamente» y «sin exclusión de todos los motivos determinantes que proceden de las inclinaciones» ${ }^{83}$, como, por el contrario, sucede en el concepto de la obligación, y sin que en el ámbito de las opciones pueda trazarse la linea fronteriza entre lo permitido y lo no permitido. Incluso esto último sólo puede tener lugar en el modo asertórico de la segunda categoría modal, y conectando su aplicación con el factum de la razón. La distribución y su resultado, en la fase en la que todavía ha de realizarse el tránsito sin el factum de la razón (es decir, la fase del tránsito que acaba de ser «introducido»), son simplemente problemáticos. De ahí, que con lo que se denomina «permitido» tampoco se describa lo moralmente posible bajo un imperativo categórico ${ }^{84}$, sino sólo lo que es posible desde un punto de vista moral. Esto es, lo posible desde el punto de vista «práctico-objetivo», en la medida en que de este modo todo esto esté en armonía con una posible prescripción, pero no en la medida en que esté en contradicción con aquélla, como sucede con lo que de esta manera resulta no-permitido ${ }^{85}$. En la razón práctica yace, precediendo al tránsito hacia la razón pura práctica y a sus principios, una condición que es pensada como lo permitido y lo no-permitido, para dicho tránsito, cuya realización es, comparado con aquélla (y desde la perspectiva de la consciencia de la libertad mirando hacia el factum de la razón), lo condicionado, aunque de contenido incondicionado. En relación con estas dos categorías modales de la libertad, la tercera categoría de la modalidad determina la obligación como perfecta (esto es, que no deja margen de actuación para la decisión) en contraposición a las imperfectas, en cuyo ámbito sí que existe un tal margen para el arbitrio. Esta determinación tiene lugar como una combinación de los contenidos conceptuales de las dos categorías modales mencionadas, por medio de los cuales lo que en la segunda todavía está condicionado se hace incondicionado.

3. Con el listado esquemático de las categorías de la libertad y el orden que ello implica para éstas, se conecta un sentido. Las categorías sirven para al enjuiciamiento de objetos de la razón práctica «en consideración a los conceptos de lo bueno y lo malo». Conciernen a la actividad que determina el objeto de aquella razón, en su tránsito desde la razón práctica determinada por los sentidos hacia la razón pura práctica, y toman en consideración la efectualización de la libertad, a través de la cual el objeto adquiere su determinación, como lo que ha de ser enjuiciado. Dichas categorías tienen en cuenta lo específico del objeto en cada caso, según los cuatro aspectos para las formas lógicas del juicio, y esto, respectivamente, en tres conceptos, o pares conceptuales. En cada uno de los cuatro aspectos, pero ordenados sistemáticamente, son pensadas de este modo en cuanto: 216 y ss

${ }^{82}$ Cfr. las pertinentes reflexiones que para ello formula S. BoBzIEn: Die Kategorien der Freibeit, ibid.,

$83 C f r ., \ll \mathrm{KpV} \gg, 143,118$.

84 Esto es lo que, con razón, se argumenta contra S. BOBZIEN, cfr. B. HAAS, Die Kategorien der Freiheit, ibid., 73 y ss; S. BoBZIEN, Die kategorien der Freibeit bei Kant, ibid., 213 y ss.

${ }^{85} \mathrm{Cfr}$. «KpV», 21 (nota a pie de página). 


\section{A la cantidad:}

los principios prácticos, en la medida en que dejan a la razón práctica determinarse

1. Subjetivamente, según máximas.

2. Objetivamente, según prescripciones cuyo contenido es empírico.

3. A priori, tanto objetiva como subjetivamente, bajo leyes en caso de que existan.

\section{A la cualidad:}

reglas (subsumibles bajo los principios en silogismos prácticos):

4. De la acción.

5. De la omisión.

6. De la excepción de una conclusión.
3. A la relación, que tiene la determinación de la razón (según el 1 y el 2), con:

7. La personalidad substancial.

8. El estado de la persona sobre el estado de otra.

9. La recíproca relación de una persona.

4. A la modalidad:

el resultado de la determinación de la razón según el 1 - 3, en la medida en que se cualifica o discualifica como (no sin una prescripción, pero sólo de modo problemático):

10. Lo permitido y lo no permitido.

- (bajo, por lo menos, una ley).

11. La obligación y lo contrario a la obligación.

- (la obligación, que se encuentra en el ámbito de la ley y de la prescripción).

12. Perfecta e imperfecta.

Tanto los principios de la moralidad, como lo pensado en las correspondientes categorías sólo pueden «ser presentados dogmáticamente» ${ }^{86}$ una vez que la ley, a través de la justificación de su imperativo categórico, se ha demostrado, o, por lo menos, en la medida en que el factum de la razón se haya completado. Presumiblemente, las categorías de la libertad, incluso, permiten, en cuanto al mencionado tránsito, «que... se visualice en su totalidad... el plan de aquello en que haya de consistir la realización de la prestación» — «incluso, cada pregunta de la filosofía práctica que haya de ser contestada, y, al mismo tiempo, el orden que haya de observarse»- (ibid., 119). ¿Qué se puede conocer a partir de una tal visión de conjunto, en cuanto a la validez prácticoobjetiva de las categorías, y una suprema ley permisiva eventualmente exigible para éstas?

No sería difícil mostrar, hasta qué punto, el pretendido orden que ha de ser observado es válido, para la determinación problemática del objeto de la razón pura práctica, respecto a los cuatro cuadrantes y según las 12 categorías. Otro tanto, por lo que se refiere a los primeros pasos en el tránsito desde la razón práctica determinada por los sentidos hacia la razón pura práctica, así como hacia los principios de la moralidad. Para ello, no hay más que sopesar posibles leyes obligatorias y permisivas que hacen idóneas a las categorías, para la determinación correspondiente. También parece incuestionable que, cuando el imperativo categórico de la moralidad se justifica, o

$86 \ll \mathrm{KpV} », 118$. 
se toma en consideración al factum de la razón, algunos principios se dejan plantear dogmáticamente en los cuatro aspectos de la función de determinación y enjuiciamiento que las categorías de la libertad tienen. Desde el punto de vista de la cantidad, existe entonces una ley práctica, además de máximas y prescripciones. Al amparo de la cualidad de las reglas que bajo el ámbito de esta ley entran en consideración, para la aplicación de nuestra máxima, existirán, eso sí, reglas para la acción y la omisión, pero, en cualquier caso, no existirá ninguna regla para la excepción. Por lo que se refiere a la relación, toda determinación de la voluntad y del arbitrio tiene, en cualquier caso, que ver con la persona, en la medida en que no es sujeto empírico de la voluntad, así como con el estado en el que dicha persona se encuentra, incluido el estado de la predisposición a la observancia o no de la ley. Y, por último, en el ámbito de la modalidad, la acción de conferir una determinada forma a todas las máximas y dejarse guiar, exclusivamente, por máximas que tengan esta forma, es, como mínimo, obligación en contraposición a lo que infringe la obligación.

4. ¿Pero cómo se entiende esto en relación a la diferencia entre obligaciones perfectas e imperfectas, esto es, a la singularización de las primeras con respecto a las segundas? Los principios necesarios para ello no son planteables, dogmáticamente, de forma completa, a través de la ley expresada en el imperativo categórico de la moralidad. Y ello, a pesar de que esta ley suministra, para la exclusiva formación y apropiación de máximas que se ajusten a su imperativo, una inequívoca obligación que no concede margen de actuación alguno. La razón es bien sencilla: cada una de las posibles acciones individuales que, enjuiciadas únicamente según el imperativo categórico, se ejecuten en el cumplimiento de aquella obligación, quedan en gran medida indeterminadas, además de que en dicho ámbito queda un gran espacio de lo indiferentemente permitido ${ }^{87}$. Sin embargo, ninguna de estas indeterminaciones es definida a través de una segunda especie de obligaciones, esto es, las imperfectas. Ni tampoco se delimita el ámbito de las obligaciones perfectas del de las imperfectas. Sólo sería posible una delimitación de principios, así como su planteamiento dogmático, si, además de la ley obligatoria que está contenida en el imperativo categórico de la moralidad, existiera una ley permisiva, bajo la cual — dentro de la limitación del arbitrio que acomete el imperativo categórico- existieran márgenes de actuación permitidos para la acción, explícita y normativamente establecidos. Sin embargo, el propio imperativo categórico de la moralidad no contiene ninguna necesidad para ello, ni para otras leyes obligatorias o permisivas. Tampoco queda determinado, por medio del imperativo categórico, cómo se comporta éste bajo otras eventuales normas que contienen reglas de excepción (según la categoría 6), ni lo que haya de significar, en cuanto a principios para la recíproca determinación de una persona en relación a otras personas (según la categoría 9). Después de todo lo que se ha expuesto acerca de una ley permisiva que flanquea al imperativo categórico de la moralidad, y sus consecuencias, es probable que también necesitemos de una tal norma.

Que sería, en principio, compatible — por lo tanto, posible sin contradicciónuna norma permisiva con una norma obligatoria, ya fue demostrado haciendo referencia al texto kantiano de la paz perpetua $(3,1,3)$. Si, además de dicha compatibilidad, fuera inevitable, junto al imperativo categórico de la moralidad, una tal norma permi-

$87 C f r$. KANT über AdiaPHORA: «MS» (409); $A$. A. XXVII, (513) (Metaphysik der Sitten Vigilantius). 
siva, ésta ya no dejaría el concepto de lo permitido (diferenciado de lo no-permitido), simplemente, como categoría residual (dentro de lo moralmente indiferente en dicho ámbito) - tal y como se exige para la categoría 12, bajo una prescripción en el ámbito de la norma obligatoria-. Más bien, la norma permisiva integraría el concepto de lo permitido - modificado, a su vez, en un concepto de lo permitido normativamenteen el concepto de aquello que es obligación. Y lo integraría como el concepto de un margen de actuación permitido que se abre inmediatamente con la obligación impuesta, para acciones con las que se lleve a cabo el cumplimiento de dicha obligación. De este modo, la ley permisiva haría posible el planteamiento dogmático de principios, para las obligaciones imperfectas. Y, a través de los límites de su extensión, también haría posible la mencionada ley la delimitación de las obligaciones imperfectas frente a las perfectas. Sólo por medio de la ley permisiva —en su otra función más fundamental - sería posible dar también una definición real de lo moralmente posible, y, con ello, su delimitación frente a lo simplemente permitido bajo una prescripción. Para que la doctrina de un objeto de la razón pura práctica pueda ser expuesta, según el plan de las categorías ordenadas sistemáticamente, se requiere, indudablemente, de la prueba que no sólo estamos situados bajo el ámbito del imperativo categórico de la moralidad, sino también bajo el ámbito de un principio que se le añade, y que es la ley permisiva.

\subsection{Razones a partir de las cuales la ley permisiva ha de ser asumida y su existencia deviene comprensible}

¿Pero por qué, con qué contenido y cómo, tiene carácter necesario lo que en ello ha de ser demostrado? Para entender bien la razón, habría de considerarse que una necesidad en la cosa misma no debería demostrarse en aquello para lo que se la necesita, sino en algo otro, donde radica su fundamento. En nuestro caso, por lo tanto, no en el objeto de la razón pura práctica, sino en la misma razón pura práctica. Se podría, por ejemplo, argumentar que la razón pura práctica tiene que darse a sí misma una ley permisiva - no porque en caso contrario no se llegue a determinación alguna de las efectualidades de su causalidad, que son acciones moralmente posibles, esto es, acciones hechas posibles en la razón pura práctica, ni porque ni siquiera se llegue a la determinación de obligaciones imperfectas- sino, más bien, al revés: porque en caso contrario la razón pura práctica no sería razón. Y es que ésta, como tal, se dirige hacia la completa determinación de su contenido, y como práctica, hacia la completa contestación a la pregunta de qué debemos hacer. Pero, además, porque, en caso contrario, no sería posible contestar sistemáticamente «cada pregunta de la filosofía práctica», como había pretendido KANT en el contexto de las categorías de la libertad. Probablemente, la argumentación no sería incorrecta, pero sí demasiado abstracta; desconectada de modo insatisfactorio del factum de la razón, al que hemos de atenernos para no perder el suelo del conocimiento práctico, y olvidadiza en cuanto a la situación del tránsito desde principios de la razón práctica en general hacia los de la moralidad. Cuando menos, requeriría de concreción.

1. La argumentación podría, en cuanto a la diferencia entre obligaciones perfectas e imperfectas, ser de esta guisa: cada máxima lo es para la acción. La acción 
ha de ser, si estoy indirectamente vinculado a ella, una acción cualificada por medio de la máxima. Ahora bien, dicha acción no puede estar cualificada solamente por su finalidad, sino que ya ha de permitir de suyo una descripción bajo la cual sea idónea, inidónea, o, en cuanto al fin, indeterminada. Incluso, aunque el imperativo no determine directamente una acción obligatoria, sino que sólo llegue a ser determinante para la acción, indirectamente, a través de una máxima, sí que, en todo caso, ha de significar (bajo una u otra descripción) una, o algunas acciones de entre las que se encuentren a disposición «en el acopio», para poder determinar una acción. En cualquier caso, ha de ser posible fijar explícitamente, a través del imperativo, si al arbitrio del que actúa se le concede un margen de actuación en el tránsito hacia la decisión, o, si el proceso de reflexión acerca de la acción que se ajuste al fin ha de prolongarse hasta que sólo quede, bajo una descripción muy determinada, una acción, como la única que más se ajusta al fin. Esto resulta imprescindible, si no se quiere que la reflexión (acerca de la aplicación de la máxima a una acción) que, co-ordenada por el imperativo, ha de ser puesta en marcha para ello, acabe simplemente en un ámbito de acciones vagamente apuntaladas bajo una u otra descripción, en lugar de conducir a una decisión, para una acción determinada bajo una descripción determinada. En caso contrario, no se lleva a cabo la determinación de una acción obligatoria — aunque sea indirectamente-, sino que solamente se establece un marco, para la determinación de acciones obligatorias. Que la determinación indirecta de la acción obligatoria deja explícitamente un margen de actuación para el arbitrio (en el tránsito hacia la decisión), lo dicen las expresiones «obligatio imperfecta» y «obligatio lata». La obligación no es imperfecta porque en supuestos reglados se permitan excepciones a la regla, esto es, derogaciones singulares, sino porque sólo se establecen máximas de una forma determinada. Pero, el procedimiento, según estas máximas, para la determinación de acciones por las que uno se decide en cada situación (es decir, en cada variante), deja al arbitrio la elección, en cada caso, de una acción entre las varias que se ajusten a distintas descripciones, y que, en la medida en que se pueda pre-ver, sean idóneas, o, por lo menos, no inidóneas, para la realización del fin. De ahí, que a las obligaciones imperfectas también se las conozca como «obligaciones alternativas» ${ }^{88}$. Estas obligaciones conceden a la persona (que tiene una máxima en forma de mandato, de cuya «aplicación» se trata) la facultad de decidir, «hasta qué punto puede cumplirse el fin prefijado, para él, por la humanidad, ya sea para su propia persona, o, para la felicidad de otros» (op. cit.). Pero, para, a pesar de ello, obligar a alguien con carácter necesario, por medio de la norma, a la realización de acciones - aunque sólo sea indirectamente, esto es, imponerle acciones que constituyen un deber, ha de hacerse explícita la permisión de una elección-. Esto no puede suceder sin una ley permisiva.

$\mathrm{El}$ argumento, además, se deja reforzar por el indicio de que sin la ley permisiva (y las que ya han sido consideradas como sus consecuencias) alguien que quiera cumplir (cuando menos, según su propia interpretación) el imperativo categórico de la moralidad puede caer en un proceso imprevisible de escrupulosa búsqueda de la mejor forma posible, para sus máximas y sus aplicaciones en casos concretos, con el objeto de llevar a cabo el cumplimiento de obligaciones perfectas por medio de acciones que, para la observancia de tales máximas, sean las más idóneas. Además, la persona en cuestión

${ }^{88}$ A. A. XXVII, (578). 
probablemente necesitaría en dicha búsqueda postergación de la acción ad Calendas Graecas, para no estar expuesto a error o fallo alguno en la observancia del imperativo categórico de la moralidad. El argumento consiste en que la razón pura práctica, en su causalidad adecuada a fines, ha de tener un objeto concreto, que, en un principio, consiste en un fundamento de determinación para la voluntad, a continuación, en acciones individuales, y, por último, en acciones externas. Pero, la clave del argumento está en que aquella razón pura práctica no puede llegar a un tal objeto sin una ley permisiva.

2. Probablemente, las razones que, en el camino de una tal argumentación en sus distintas variantes, puedan movilizarse para una ley permisiva, no sean lo bastante específicas, en cuanto a la cuestionada necesidad del derecho. Esto se debe a que dicha necesidad sólo se da, si la ley permisiva de la que aquí se trata ya posee relevancia, para una disposición personal que - en el tránsito por investigar — todavía precede a la disposición que se orienta hacia la observancia del imperativo categórico de la moralidad. El imperativo categórico de la moralidad se dirige a mí como alguien que se encuentra en esta disposición «natural», en la medida en que me lleva a la consciencia de la libertad inteligible de mi personalidad — es decir, a la consciencia de lo humano en mi persona- y me representa de modo efectual la necesidad de dejar que la norma que me doy a mí mismo llegue a constituir el fundamento determinante de la efectualidad de dicha libertad. La pregunta es, por lo tanto, si por medio de esta legislación ya puedo hacer uso de una ley permisiva para mi acción, incluso, en el ámbito de la disposición de la razón práctica condicionada por los sentidos, y si no puedo evitar cerciorarme de esta ley permisiva en la consciencia de mi libertad y del imperativo categórico de la moralidad, con anterioridad al cambio de disposición ordenado por dicho imperativo.

En la perspectiva de la autodeterminación de la razón pura práctica ( $c f r$. D. 1) tenemos, por lo tanto, que concentrarnos en su estructura de arranque. La razón estriba en que ya se requiere de la permisión en el ámbito de una predisposición que precede a la intención de cumplir el imperativo categórico, y que concurre en mí, una y otra vez, con esta intención. Ahora bien, es indudable que la permisión de la que se trata no puede ser ni la meramente problemática bajo el ámbito de una prescripción (según la categoría 10), ni la de lo moralmente indiferente. Esto se debe a que, si la razón pura práctica constituye una unidad consigo misma en su actividad legislativa y su determinación de la voluntad, dicha razón pura práctica es también permisión moral, para llevar a cabo el tránsito desde la disposición natural hacia la disposición de cumplir con el imperativo categórico de la moralidad. Esta permisión es, desde el punto de vista moral, de suma importancia. No se trata un simple adiaphoron. Es más, la permisión ha de abarcar todo lo que por medio del imperativo categórico de la moralidad no está prohibido, puesto que me ha de poner en situación de movilizar mis fuerzas en toda su extensión, para el tránsito. Es precisamente en el ámbito de esta extensión en el que la permisión es relevante, para la necesidad del derecho, aunque sólo sea con opciones puestas en el arbitrio que atañen a la acción externa, y a la influenciabilidad del arbitrio ajeno. $\mathrm{Y}$ es relevante como una permisión que pertenece a la disposición natural de la persona, desde el momento en que ésta toma consciencia del imperativo categórico de la moralidad. Y ello tantas veces, como las que, desde la intención de cumplir con el mencionado imperativo, recaiga una persona en la disposición natural, puesto que, solamente en el supuesto de dicha disposición, las obligaciones y facultades jurídicas no son, indirectamente, éticas, sino jurídicas sin más. 
3. Ahora ya tenemos el argumento decisivo en la mano: sin duda, que la cuestionada permisión ya existe en el ámbito de la disposición con la que tiene que ver el derecho, y, precisamente, en la extensión exigible para su necesidad. Y ello, porque dicha permisión no puede ser ni la de lo meramente permitido en una prescripción, ni la de la indiferencia moral. Ésta, a diferencia de la permisión, se da — si acaso- - secundariamente, y no sólo con respecto a la prohibición, sino también al mandato bajo el imperativo categórico de la moralidad. Y, en todo caso, se da para quien se somete al mandato. Pero la clave está en que ya con anterioridad a la disposición requerida para someterse al mandato, tenemos certeza de la cuestionada permisión. Esta certeza no la podemos retrotraer más que a la razón pura práctica, que, como autolegislativa en el factum de la razón, y consciencia de nuestra libertad, llega con la norma obligatoria de nuestra disposición, pero con anterioridad a su observancia. Dicha certeza no sólo se manifiesta con aquella norma obligatoria, sino también con una ley permisiva, solamente a través de la cual podemos ganar la disposición adecuada. De ahí que tengamos que tener la certeza de la ley permisiva. Que «tú puedes, puesto que debes» incluye, si se piensa con exactitud, su perceptibilidad. La «percepción» de la permisión (en sentido teórico y práctico) no puede ser engañosa, si la razón pura práctica, en el factum de la razón y en la consciencia de nuestra libertad, no nos engaña. Pero, para hacer esto, tendría que engañarse a sí misma, o no ser la nuestra. Sin percepción de la permisión ya existente en la disposición natural, sería el tránsito hacia los principios de la moralidad un milagro, o no sería lo que, por decaimiento de lo natural, conduce hacia la libertad autónoma que es el encuentro con uno mismo. Sería, más bien, la neurótica autocoacción «prusiana», de cuya predicación es acusada una y otra vez, por error, la doctrina del imperativo categórico de la moralidad kantiana. En cualquier caso, el tránsito ya no sería obra de la razón pura práctica. Tampoco nos podría aclarar lo que significa decir de una acción que sólo posee legalidad, puesto que ya habría de estar permitida por el juicio moral, para poseer una tal legalidad. Si, por el contrario, ya existe la permisión que aquí interesa en la disposición natural y, a su vez, tenemos consciencia de ella, nos protegerá frente a la posibilidad de que el cambio de predisposición que nos exige el imperativo categórico de la moralidad se convierta en una acción contradictoria en sí misma. Esto es, una acción que ya debería ser llevada a cabo como obligación por la obligación, no pudiendo, por lo tanto, cumplirse desde la disposición de la que presumiblemente nos saca. O bien, una acción que sólo sería puesta en funcionamiento del arbitrio natural al amparo de prescripciones empíricas, esto es, en ningún caso un acto de libertad autodeterminante.

4. FICHTE se dio cuenta con acierto de que la situación del tránsito a la que hay que entender referida la ley permisiva, tiene semejanza con la de la superación del estado (jurídico) de naturaleza en el avance hacia un estado de paz civil. Pero sacó de ello conclusiones del todo falsas. Esto se debe, entre otras cosas, a que no vio las diferencias sustanciales entre ambas situaciones. La permisión vigente para una disposición de la persona, distinta de la disposición moral, ni contiene una licencia para aplazar el tránsito, ni la exención de una prohibición ${ }^{89}$. Lo único que hace dicha permisión es conferirle a la permisión, para el estado de la disposición natural, carácter de ley. Una parte de dicha permisión sería, en el ámbito de la intención de cumplir con el imperativo

\footnotetext{
89 A. A. VIII, (347 y ss).
} 
categórico de la moralidad, la permisión de lo indiferentemente permitido, si no fuera porque junto con la otra parte - esto es, según el factum de la razón y la consciencia de libertad- se trata de una permisión como consecuencia de una lex permissiva. Dicha ley, a diferencia de una ley permisiva para un estado (jurídico) de naturaleza, ni lleva aparejada una condición restrictiva en una ley prohibitiva, ni proporciona una justificación provisional, aunque, de hecho, sí se refiera a un determinado estado de cosas. Con esta legislación y su consecuencia (a saber: la producción de leyes jurídicas) la razón pura práctica o su autonomía no «renuncian» a la idea de la obligación como motor de la razón pura práctica. Ni tampoco a la idea de la obligación para un determinado fin ${ }^{90}$. Del mismo modo que la permisión tampoco proporciona espacio para una ley obligatoria completamente distinta de la libertad práctica, ni para varias leyes de este tipo. De ningún modo, por lo tanto, hace del imperativo de la moralidad un imperativo condicionado. Es evidente que únicamente tiene como consecuencia que la determinación del objeto de la razón pura práctica, en las categorías de la libertad hasta ahora consideradas, ha de ser completada por medio de principios adicionales, los cuales han de ser pensados en posibles predicados para aquellas ${ }^{91}$.

Ahora ya se puede formular la ley permisiva y, con ello, su contenido. La fórmula sólo puede decir: cualquier persona puede en cualquier momento, lugar, y estado en el que sea dueña de sí misma, hacer uso de su arbitrio en toda la extensión en la que el imperativo categórico de la moralidad no lo prohíbe, y abstenerse en la extensión en la que el imperativo categórico no impone ningún mandato. Esta permisión, tal y como lo exige KANT ${ }^{92}$, se deja introducir en la fórmula del imperativo categórico de la moralidad sin esfuerzo, sin contradicción y sin cláusula excepcional. Referida a sus destinatarios, la ley permisiva completa el texto de este imperativo, añadiendo: «[...] con lo cual tú puedes en cualquier momento, lugar y estado en el que seas dueña o dueño de ti mismo, hacer uso de tu arbitrio en toda la extensión en la que no te resulte prohibido por este imperativo, o, en la medida en que tampoco te resulte ordenado por el mismo, hacer uso de tu arbitrio, o abstenerte de dicho uso». De suyo, debería entenderse, según lo expuesto hasta ahora, que sólo se llega a este apéndice, si al factum de la razón se le añade la consciencia de nuestra libertad, esto es, si ésta accede al factum.

5. Con el fundamento de la ley permisiva, también debería quedar claro el carácter de su necesidad. No se trata, evidentemente, de una necesidad según leyes de la naturaleza, ni tampoco de una consecuencia lógico-formal de un enunciado a partir de otro determinado, solamente, por razón de la forma y según reglas de conexión funcionales, para enunciados con dicha forma. Se trata de una necesidad epistémica en el contexto del conocimiento práctico, y, de ahí, atribuible tanto a lo que en ello es reconocido, como a su conocimiento. Pero, ambos (esto es, lo reconocido y su conocimiento) no por razón de una ley obligatoria, ni de ninguna necesidad vinculada a su producción legislativa, sino bajo el presupuesto de esta necesidad y vinculados a la

${ }^{9}$ Cfr., en contra, W. Kersting, ibid., 33.

91 Una de ellas aporta sin duda la determinación dogmática, para acciones individuales, de ser obligaciones perfectas según el tipo, para la exposición y la condición limitativa en ellas, que estas acciones son exclusivamente tales del arbitrio externo — a diferencia de la pura obligación de la virtud en cuanto sean máximas de una determinada forma y motivación, como a diferencia de algunas virtudes que son obligaciones perfectas (frente a sí mismo) [Cfr., Ibid. (421 y ss.)].

92 A. A. VIII, (348). 
justificación de dicho presupuesto, por razón de la certeza de nuestra libertad práctica. La cual se justifica de este modo, si resulta suficientemente clarificada no sólo acerca de su certeza subjetiva, sino acerca de sí misma como aquello de lo que esta misma es consciente. Esto, si dicha clarificación no sólo ha de ser considerada como cosa de la filosofía, sino como algo que ya se lleva a cabo en la razón práctica de modo asistemático e impreciso, tan pronto como la razón tenga, además de su norma fundamental, consciencia de su libertad. El conocimiento práctico inmediato, así como el filosófico, ambos en posesión de la modalidad de la certeza, y, por lo tanto, vinculados a la consciencia de la necesidad ${ }^{93}$, tienen la cualidad de una comprehensio: asen la libertad en un cierto horizonte del pensamiento, esto es, la reconocen «a través de la razón, o a priori... en el grado en el que es suficiente para nuestro propósito» ${ }^{94}$. En aquello que reconocen, tienen no sólo un fundamento del conocimiento de la ley permisiva, sino también su razón de ser. En ello comprendemos cómo nos sabemos necesariamente libres, cuando registramos en nosotros el factum de la razón, y cómo forma parte de este conocimiento ejercitar la libertad que somos como razón práctica en la autonomía que incluye la ley permisiva, y en la producción efectual, conforme a las normas que me doy a mí mismo. Por lo tanto, también comprendemos que necesariamente somos libres y cómo lo somos. La producción legislativa, esto es, la producción de obligatoriedad práctica que tanto la ley permisiva, como cualquier otra ley llevan aparejadas, tan sólo consiste en este caso en asir nuestra libertad de modo efectivo como conforme a esta ley. Pero, a continuación, la mencionada producción de obligatoriedad práctica consiste en comprender dicha libertad que hemos asido, para el uso del arbitrio externo de las leyes obligatorias que son consecuencia de la ley permisiva. La sucesiva exposición de la doctrina del objeto de la razón pura práctica, para la que aquí ya no hay sitio, tendría más que decir a esto.

\subsection{De nuevo a vueltas con el supremo principio distintivo}

Pero al igual que antes, se comprende por qué el arbitrio interno ha de ser «segregado» del externo, y, de modo recíproco, el externo del interno. La razón más profunda para ello estriba en la consciencia de la libertad que adquirimos mediante el factum de la razón en el tránsito desde la predisposición natural hacia la predisposición moral. Quien, a la vista de este factum y en la consciencia de su libertad, ya tiene la intención de cumplir el imperativo categórico de la moralidad, ha llevado a cabo, en el primer paso de dicho cumplimiento, la segregación de su arbitrio interno del externo. La razón está en que se ha de concentrar en su máxima y, sobre todo, en el motivo moral que en ello ha de subyacer, lo cual es cosa, exclusivamente, de la puesta en funcionamiento del arbitrio interno. Y quien en aquel tránsito, tal y como le está mandado, alcanza la intención de cumplir con el imperativo categórico de la moralidad, ha de efectuar, en primer lugar, la segregación en esa dirección. Aquí, la necesidad es una coacción práctica por medio del imperativo. Quien, por el contrario, no tiene la intención de cumplir el imperativo categórico de la moralidad, ni tampoco logra alcanzar este estado intencional y, por lo tanto, permanece en una predisposición natural, resulta, sin

${ }^{93}$ Cfr. I. Kant's Logik», B. G. JäschE (ed.), Einleitung IX Anfang (A. A. IX, [65] ).

${ }^{94}$ Ibid. Einleitung VIII, Schluß (A. A. IX, [65] ). 
embargo, exhortado por el factum de la razón a abandonar esa predisposición no sólo por sí mismo. También está llamado dentro de sí mismo (esto es, en la predisposición en la que se encuentra) a registrar la autonomía de la razón práctica, para una ley permisiva de mayor extensión compatible con el imperativo categórico de la moralidad. Igualmente está llamado a tomar en consideración la correspondiente permisión para su libertad. Esta toma en consideración ya es la de una exigencia moral (cuando menos de honestidad intelectual). Pero, también es cosa de la inteligencia y del autoconocimiento teórico y práctico que dicha toma en consideración, como consecuencia de la actividad autónoma de la razón pura práctica, lleve aparejada leyes para el arbitrio, para las que sea posible una legislación externa que llegue a ser efectiva en una u otra variante. Tampoco aquí está el uso del arbitrio interno sometido a limitación alguna, más allá de la que ya se haya constituido con el imperativo categórico de la moralidad, aunque en la predisposición natural todavía no haya sido tomada en consideración. Y es que como la ley permisiva autoriza a todos los seres racionales al uso de su libertad en la misma medida, han de estar las consecuencias de dicho uso cohonestadas en la propia ley permisiva, en la medida en que sean tangentes al arbitrio de otros. Como corolario, la toma en consideración de aquellas consecuencias tiene que venir restringida de modo distinto y en relación a algo otro que lo permitido en el ámbito del imperativo categórico de la moralidad, donde aparece como lo indiferentemente permitido, o lo permitido porque está ordenado. La restricción ha de venir de la mano de las condiciones del principio general del derecho, según el cual, una acción (ya proceda del arbitrio interno o externo) es conforme a derecho cuando, «como tal, o [incluso] según su máxima, puede hacer coexistir la libertad del arbitrio de cada uno con la libertad de cada uno al amparo de una ley universal» $(\mathbb{S}$ ). Para dicha restricción, y en cuanto a la «posibilidad de coexistir», sólo tiene relevancia la puesta en marcha del arbitrio externo con posible influencia en el arbitrio ajeno. De ahí, que haya de tener lugar la abstracción del arbitrio externo del interno en una predisposición natural, y de modo simétrico a la abstracción que de inmediato acompaña a la intención de cumplir con el imperativo categórico de la moralidad. Y esto no sólo en cuanto a la preparación para el tránsito hacia la intención de cumplir con el imperativo categórico de la moralidad, sino también en lo que se refiere a la preservación de la intención natural. La abstracción es, por lo tanto, una consecuencia directa de la consciencia de la libertad perteneciente a la predisposición que se genera a partir del factum de la razón, y de la consciencia de la lex permissiva que en ello y con ello es pensada. El fundamento de la abstracción no es otro que el de la propia ley permisiva, a saber: la libertad. La cual, con el factum de la razón, ya va deviniendo consciencia de sí misma como autonomía práctica en mi predisposición natural, y que constituye lo que todo ser finito que dispone de razón práctica es. Pero, como hemos visto, con la ley permisiva también resulta necesario el derecho, como conjunto de leyes que tienen por objeto de modo exclusivo la acción externa, tanto con la posibilidad de legislación externa, como interna ${ }^{95}$. Des-

95 Necesario para derecho, aunque sólo como aquella existencia que corresponde al conjunto de normas jurídicas como idea en nuestra percepción. La realidad práctica específica de este concepto (como obligatoriedad efectiva que tienen las normas a través de la legislación externa), solamente, puede ser demostrada a través de la tarea que, con la prueba de una permisión al uso de la fuerza coercitiva, es acometida para superar el problema. Sin ello, las normas jurídicas sólo tienen obligatoriedad moral interna para obligaciones éticasindirectas. Todo lo que se dice en las normas mismas —así como la norma del principio general de la ley 
de el punto de vista de los principios kantianos, podemos, por lo tanto, felicitarnos. Pero, sobre todo, por haber visto, en primer lugar, el fundamento de la necesidad del derecho, que es, a mi modo de ver, el modo en que se lo plantea KANT. Es a través de la justificación de las normas jurídicas, como también se le da un significado objetivo a la categoría de la obligación perfecta, para las acciones externas.

A ello, una consideración adicional: el joven J. EBBINGHAUS, en su escrito de habilitación hegeliano no publicado en vida sobre el HEGEL francfurtiano, caracterizaba como la «dificultad fundamental» de toda la filosofía práctica de KANT el explicar de modo convincente cómo lo externo (de una legislación) se mete en la doctrina de la moral y qué significado puede tener ${ }^{96}$. Poco después, cuando EBBingHaus se hizo kantiano, reprimió la cuestión, la cual, desde entonces, quedó atrapada en un olvido necesario. En ninguno de sus escritos posteriores se vuelve a plantear la cuestión, a pesar de que desde el punto de vista de la temática habría sido del todo exigible. Mi intención era liberar a los kantianos de la presión generada por el problema que llevó a la mencionada represión. Pero, sólo podría decir que no he hecho otra cosa más que dar la versión kantiana, para la fundamentación de que la voluntad libre en sí y para sí de un espíritu subjetivo libre en la inmediatez de su dasein es, según el oscuro planteamiento de HEGEL, el derecho. En lo que concierne a la necesidad del derecho también parece que HEGEL, quien evitó las trivializaciones, comprendió a KANT mejor que todos sus críticos kantianos — por no mencionar a los no kantianos-.

(Traducción de Oliver Bueno)

jurídica - es «mera» idea. La «razón sólo dice que esta limitada en su idea y que también puede ser limitada por otros de obra» (ibid., $\mathbb{\$} \mathrm{C}$ ).

96 «Die Grundlagen der Hegelschen Philosophie», publicado por primera vez en J. EBBinghaus, Gesammelte Scbriften, Band 4. En conexión con G. GEISMANn y H. OberER hrg. v. K. Herb/St. NACHTSHEIM/U. RAMEIL, Bonn, 1994, 240. 